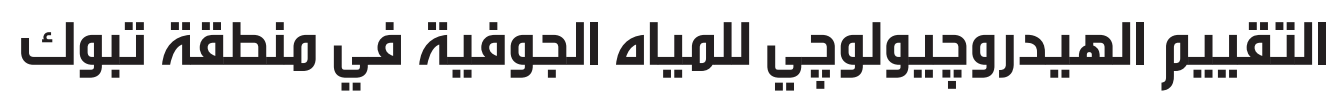
شمال غربي المملكة العربية السعودية بإستخدام نظم المعلومات الجغرافية والتحليل الإحمائي

$$
\text { أ.د. خالد بن مسلهم الحربي }
$$

أستاذ الجغرافيا الطبيعية والإستشعار عن بعد

$$
\begin{aligned}
& \text { د. هحمد عبـ الخفار البسطويسي } \\
& \text { أستاذ الهيدرولوجي المساعد } \\
& \text { قسم الجغرافيا } \\
& \text { جامعة أم القرى الجعرى }
\end{aligned}
$$

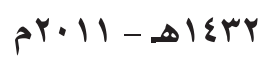


وشرقها ، ويدل ذلك على إختلاف عمق تكوين الساق. و

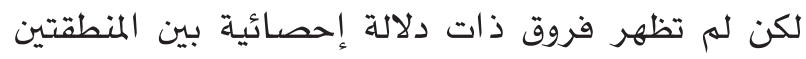

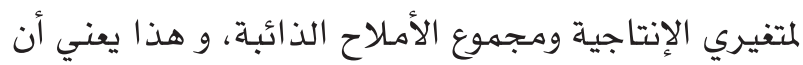

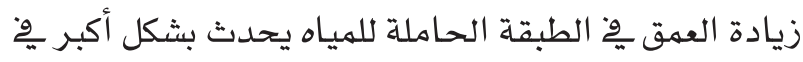

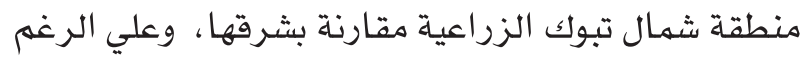
من ذلك لم تتأثر الحركة العامة للمياه الجوفية لكميات

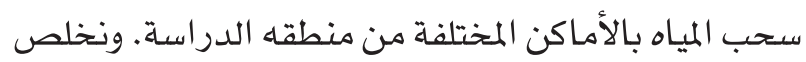

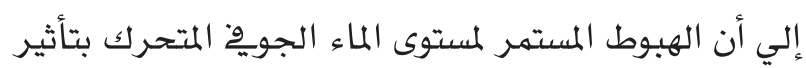

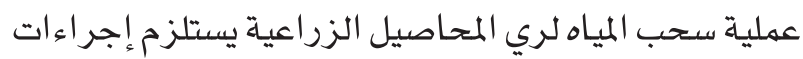

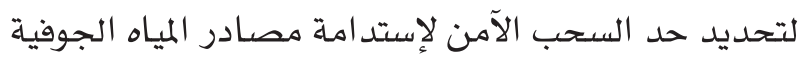

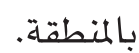

\section{ممطلحات البحث:}

المياه الجوفية- التحليل لإحصائي - أبار المياه- تكوين الساق الجمات الجات

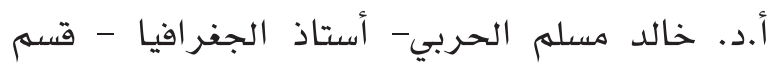
الجغر افيا- جامعة أم القرى لدي

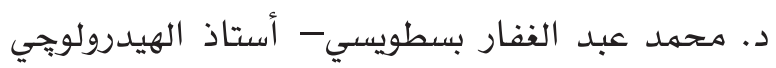
المساعد- قسم الجغرافيا- جامعة أم القرى لفيد

\section{التقييم الهيدروِيولوِي

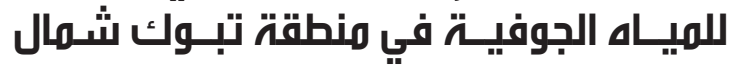

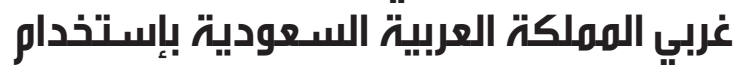 نظم المعلومات الجغرافية والتحليل الإحمائي}

$$
\text { أ.د. خالد بن مسلم الحربي }
$$

أستاذ الجفر افيا الطبيعية والإستشعار عن بعد الدري

$$
\begin{aligned}
& \text { د. محمد عبد الغفار البسطويسي }
\end{aligned}
$$

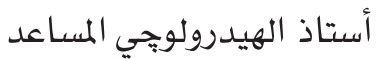

$$
\begin{aligned}
& \text { قسم الجفر افيا } \\
& \text { جامعة أم القرى الجغر }
\end{aligned}
$$

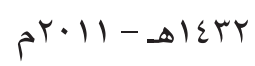

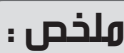

تهدف هذه الدراسة الي التقييم الهيدروهيولجي لمتفيرات

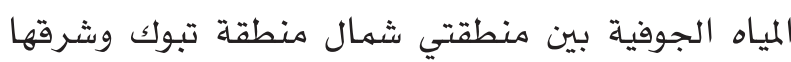

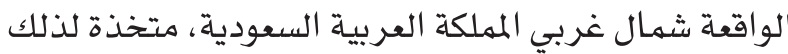

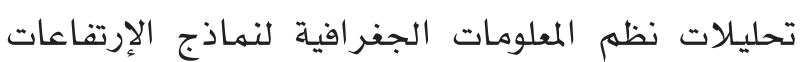

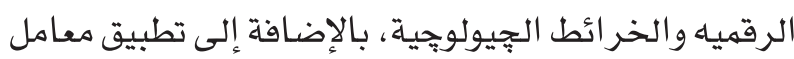

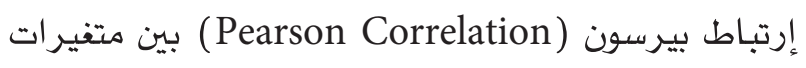

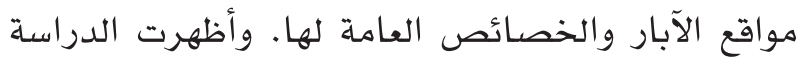

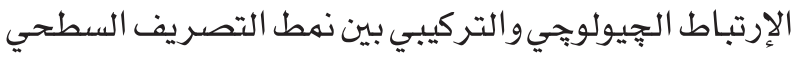

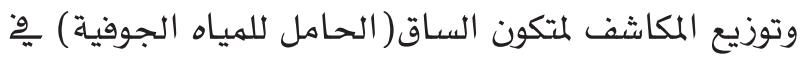

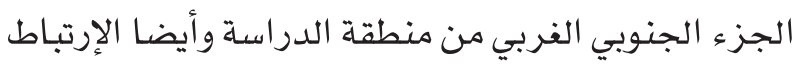

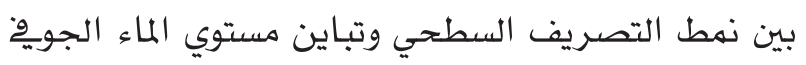

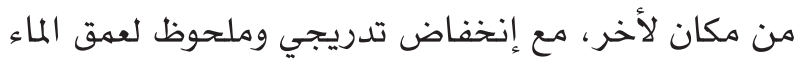

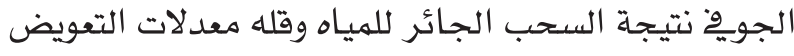
من المكاشف وأثر التراكيب الجيولوجية وِّو حركه وإتصال

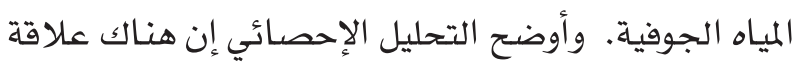

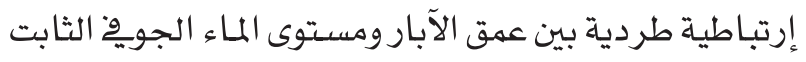
بلفت ( ^, · ) و علاقة طردية أخرى بين العمق والإنتاجية

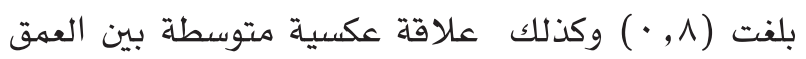

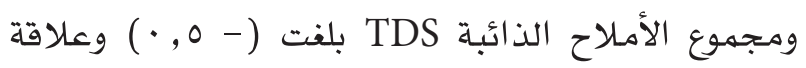

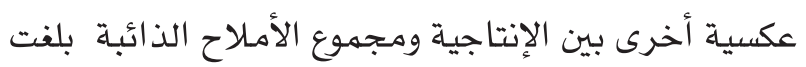

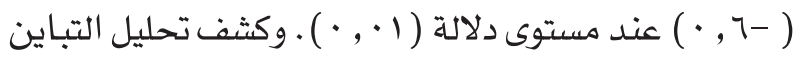
الأحادي ANOVA عن وجود فروق ذات دلالة إحصائية

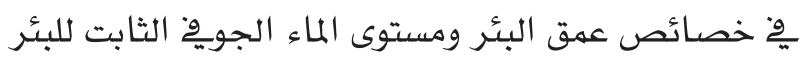

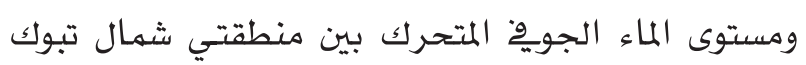




\section{HYDRO GEOLOGICAL ASSESSMENT OF THE GROUNDWATER IN TABUK AREA-NORTH- WEST OF SAUDI ARABIA USING GIS AND STATISTICAL ANALYSES}

\section{Khalid M Al Harbi, and Mohamed El bastawesy}

Geography Department of

Umm Al Qura University, Mecca, KSA.

Correspondence author:

Khalid M Al Harbi

email:alharbik2001@yahoo.com

\section{Abstract:}

This study aims to assess the hydrogeological changes of groundwater in the east and north of Tabuk regions, which is located in the northwestern part of the Kingdom of Saudia Arabia. This was elaborated using GIS analyses of DEM and geological maps as well as groundwater data collected. The ground water variables were statistically analyzed; a Pearson correlation matrix was developed for the variables of groundwater data. The study showed the geological and structural control of the surface drainage patterns and the distribution of the Saq Formation outcrops in the southwestern part of the study area, as well as the local variations of groundwater levels. The levels of groundwater are gradually declining as excessive pumping of the aquifer is of limited replenishment under the prevailing arid conditions, and the impact of geological structures on groundwater flow pattern and conductivity. The results show a high positive correlation between the depth and the water level $(\mathrm{r}=0.8)$, and another high correlation between the depth and the water production $(r=0.8)$, A negative correlation between the depth and the total dissolved salts (TDS) (-0.5) and between water production and TDS (-0.6) all at (0.01) level of significance. The Analysis of variance (ANOVA) indicated that significant differences between northern and eastern areas of Tabuk for depth, static water level, and pumping water level, as a result of the geological changes of the Saq aquifer in the eastern and northern areas. However the water production and pumping rates and the TDS of the water in both areas are correlated. This indicates that the abstraction of groundwater has not affected conductivity and groundwater flow patterns within the areas. Although the aggressive pumping of the groundwater has developed significant decline of water levels and the safe yields and sustainability of groundwater has to be examined.

\section{Keywords:}

Groundwater - Statistical analysis - Water wellSaq Formation 
وبوجه عام، فإن تكوين الساق المائي ينحدر من الغرب

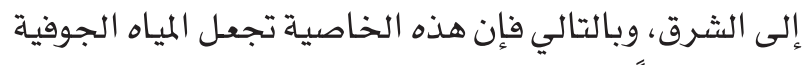
تختلف عمقاً ووفرةً من موقع إلى آخر ِِّ منطقة الدراسة. وتؤدي عملية الحفر العشوائي لآبار المياه الجوفية بِ

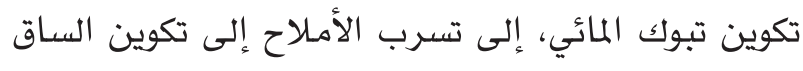

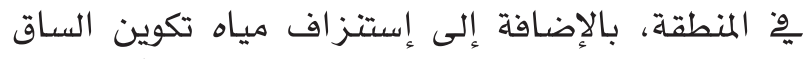

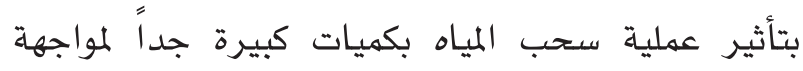
التوسع الزراعي، وتلبية حاجة مدينة تبوك من المياه. لذاه الذاه

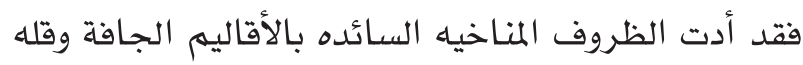
سقوط الأمطار الي تزايد وتنامي الإهتمامات بدراساه

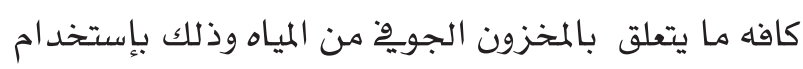
العديد من الوسائل التقنيه والعلميه والقياسات الحقليه الحنيه

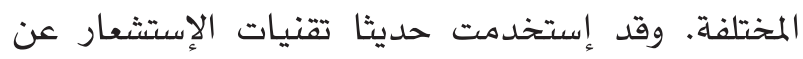

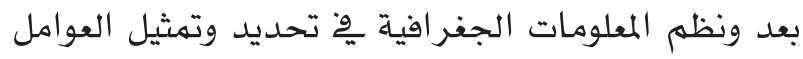

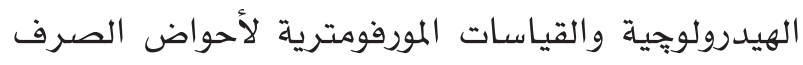
بالمناطق الجافة وأثارها علي نهط التصريف السيلي وشحن الختان الخزانات الجوفيه من مياه السيول ( البسطويسي وأخرون

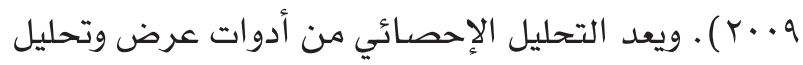

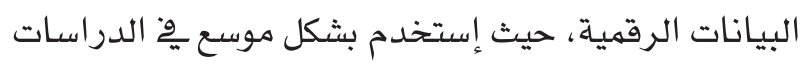

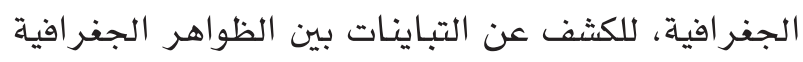

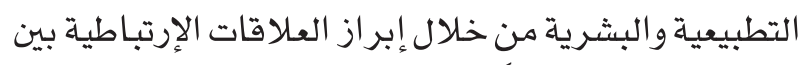

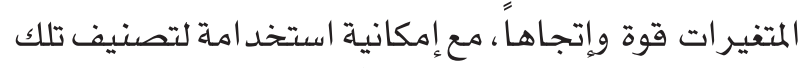

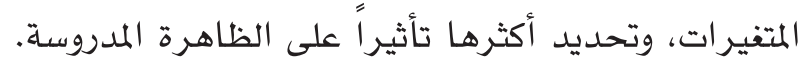
وإتجهت بعض البحوث الجفرافية الخاصة بالموارد المائية

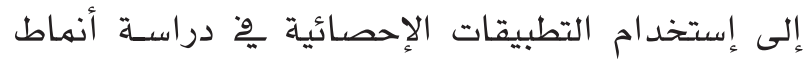
توزيع أبار الميـاه الجوفيـة، وتحليل العلاقة بين متفيراتها

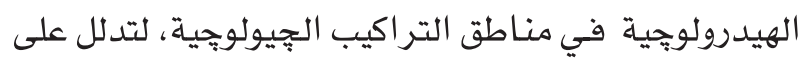

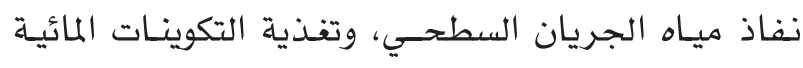

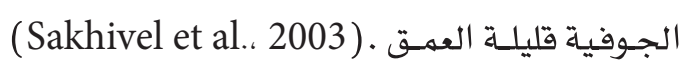
وِّْ هـذا البحث سـوف تستخدم نظم المعلومـات الجفر افية

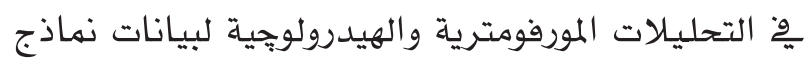
الإرتفاعات الرقميه والخرائط الجيولوجية وصور الاقمار

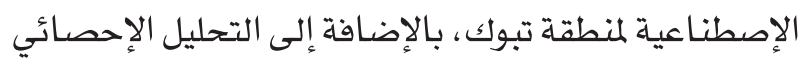

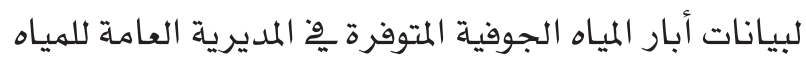

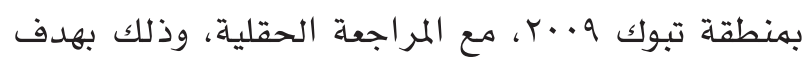

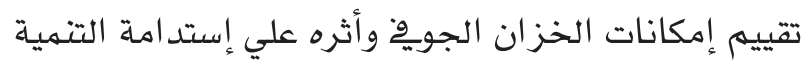
بالمنطقة.
: مقدمبة

إهتمت دراسـات جفر افيـة عديدة بالتركيز على مؤشـرات

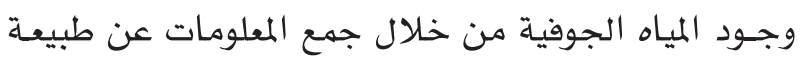

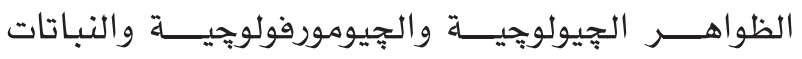

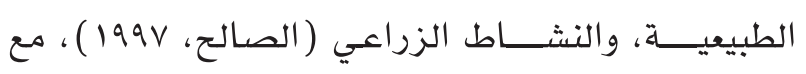

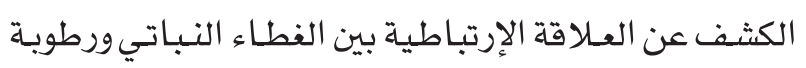

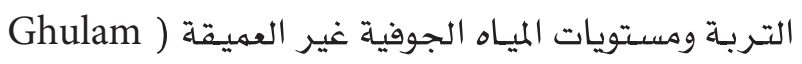
et al.، 2004

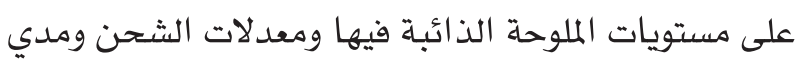

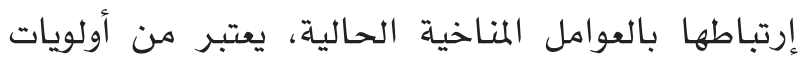

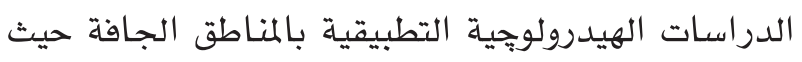

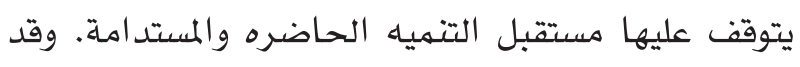
تكونت معظم المياه الجوفية بالمناطق الجافة بفعل عمليات التهيه

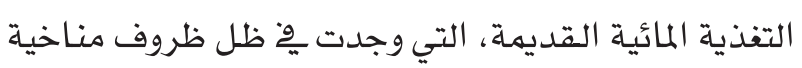

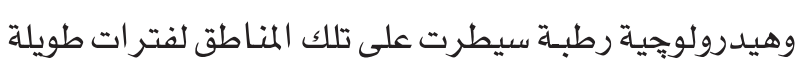
( Kayane،1997 )

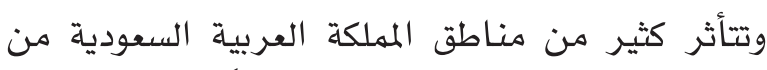

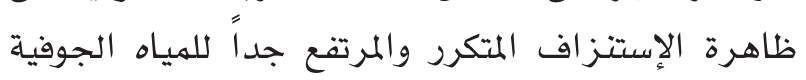

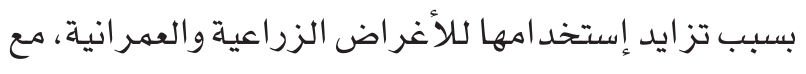
قلة فرص التعويض المائي وِّ طبقات المياه الجوفية العميقة.

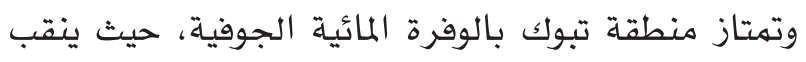

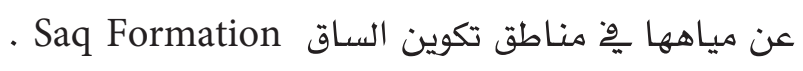

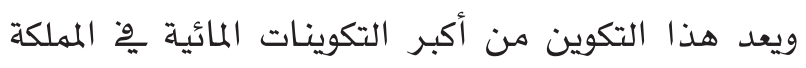

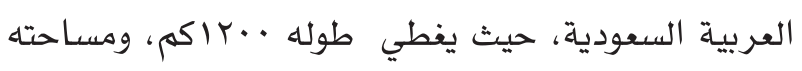

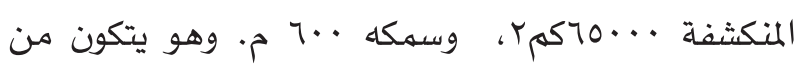
الحجر الرملي الذي يعود إلى العصر الكمبري، يعلوه طفل ملكل

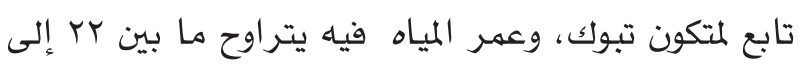

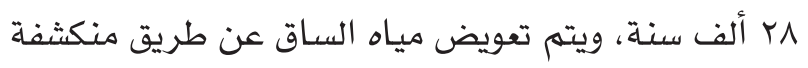

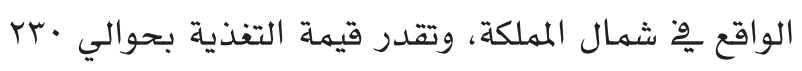
مليون مץ// سنة. ويضاف إلى تكوين الساق ويوازيه ويعلوه Tabuk Formation

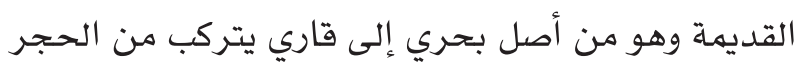

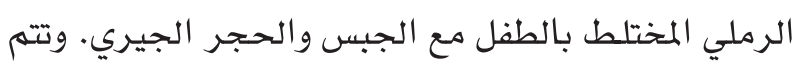
تغذية تكوين تبوك عن طريق الرواسب الرملية التي تقع إلى الى الى التيري

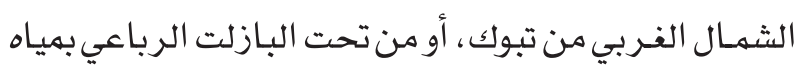

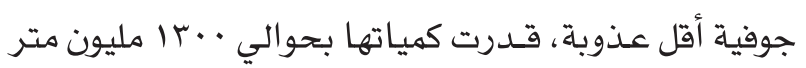

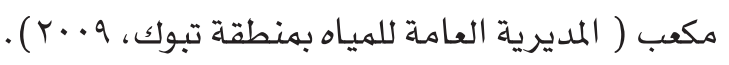




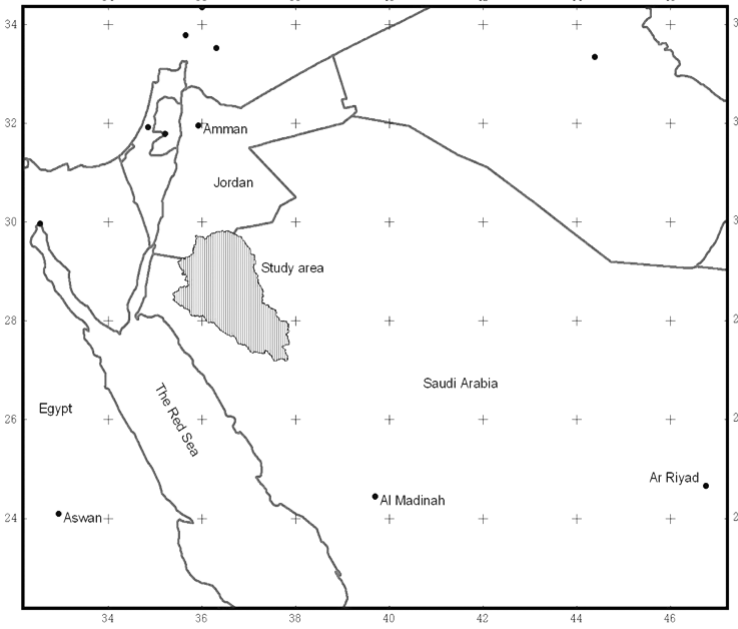

شكل ( 1 ) موقع منطقة الدراسة

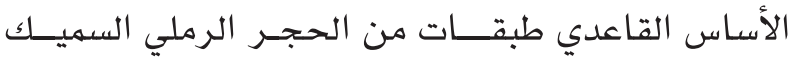
(متكون الســـاق) الذي ترسب خلال العصر الكامبري. وقد إستمر ترسيب الصخور الرملية والفتاتية خلال فتره

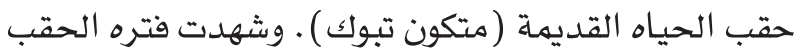
الثلاثي ترسبات لصخور الحجر الجيري الطباشيري

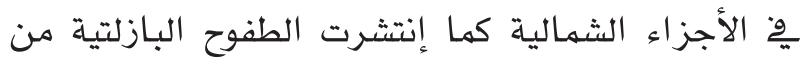

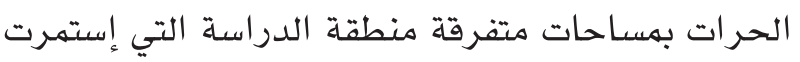

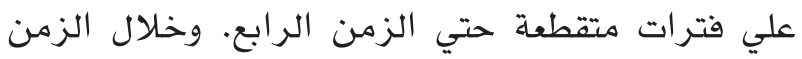
الرابع تكونت العديد من البحيرات الحبيسة والأودية

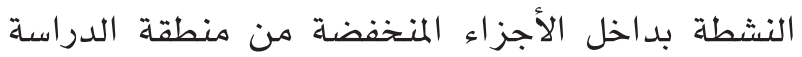

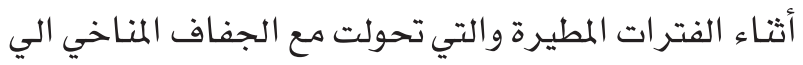
سبخات وبلايات، وكذلك شكلت العمليات الهوائية العديد من التجمعات والفرشات الرملية بمناطق الأودية القديمة

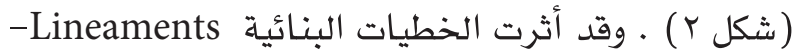

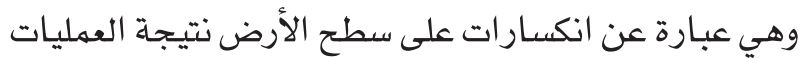

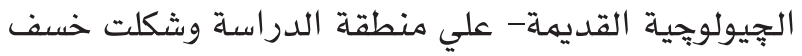
Graben (إتجاه البحر الأحمر ) . وتتاثر العديد من الأودية السطحية

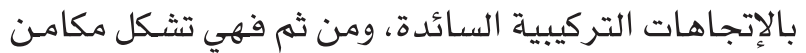
لتفذية التكوينات الجوفية غير العميقة بتأثير عمليات

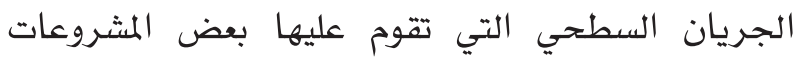
الزراعية. ويتضح من تفسير الخريطة الجيولوجية أن الن التيان بعض القيعان تمثل مناطق محلية لتجميع تصريف الأودية پِّمنطقة الدراسة قد تكونت بفعل مجموعاه من الفوالق شرق-غرب والتي خفضت منسوب بعض القطاعات الطولية

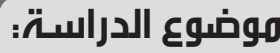

تعد دراسة المياه الجوفية توزيعاً لمواقعها ، وتحليلاً للعواهل

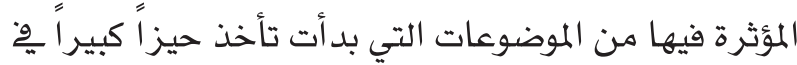
مجال الدراسات الجفرافية التطبيقية. وتأني دراسة تقييم التغير بِّ الخصائص الهيدرولوجية لآبار المياه الجوفية بإستخد امنظم المعلومات الجغر افية والتطبيقات الإحصائية وْْ منطقة تبوك كواحدة من تلك الدراسات الجفرافية بقصد التعرف على الفروق يُّا الخصائص الهيدرولوجية لآبار المياه الجوفية بين شمال وشرق تبوك على إعتبارهما موقعين زراعيتين بِّ المنطقة (شكل ا ).

\section{هدف الدراستة:}

يتحدد الهدف الرئيسي للدراسة پِّ التحليل المورفومتري والجيولوجي لحوض الصرف بهنطقة تبوك، وتحديد اثر

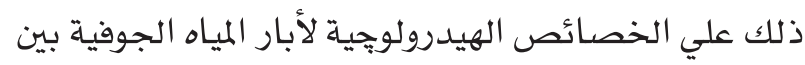
منطقتي شمال تبوك وشرقها.

\section{تساؤل الدراسة:}

هل هناك فروقات ذات دلالة إحصائية ِِّْ الخصائص

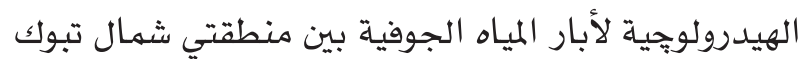

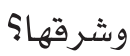

\section{منطقة الدراستة:}

تقع منطقة تبوك بِّ الطرف الشمال الغربي من المملكة العربية السعودية، وتعد من مناطق المملكة التي تشهد

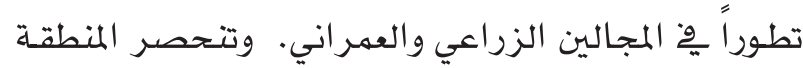

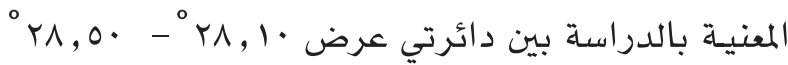

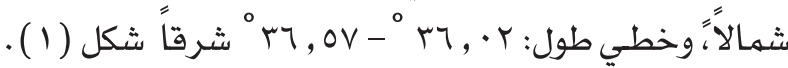
وتظهر علي سطح منطقه الدراسة عده أنواع مختلفة

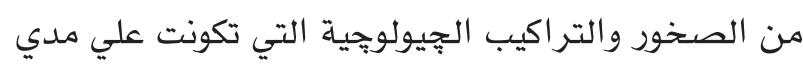

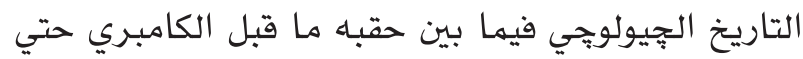

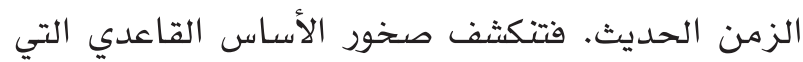

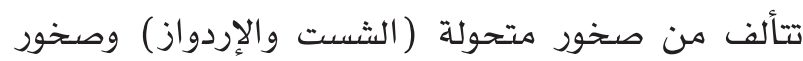

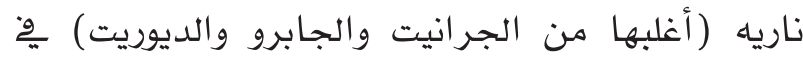
الجزء الغربي من منطقة الدراسة. وتاثرت هذه الصخور بالحركات الأرضية المختلفة وتكونت بها طيات الدرات وكسور و العديد من القواطع النارية والعروق. وتعلو مجموعة صخور الارضية 
ويتســم منـاخ المنطقــة بصفته القاريـة، حيث تبـدو الفـروق الحر ارية اليوميـة والشهريـة والسنويـة الكبيرة، فتهـار أشهر صيفها شديد الحـر ارة وليلها معتدل، وشتاؤها معتدل نهاراً

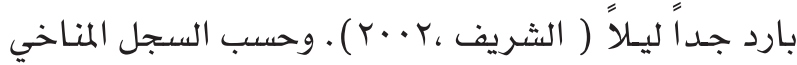
للهنطقة، تصل المعدلات الحرارية الصيفية إلى مب درجة مئوية، وتتخفض شتاءً إلى ما يقارب خمس درجات مئوية خلال الفترة من ديسمبر إلى فبراير، مع التباين الواضح

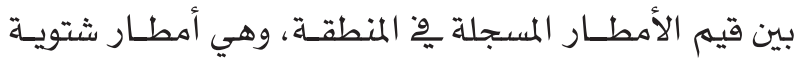

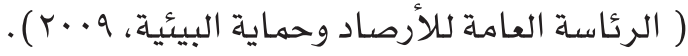

للأودية شمال غرب-جنوب شرق عما حولها، وأصبحت العديد من هذه القيعان تتصل فيما بينها بقنوات فيضية overflow channels بالمنطقة. وقد تؤثر تلك المجموعات من الفوالق علي منسوب وإتصال وحركه الماء الجويْ بالمنطقة. وعموما ترتبط

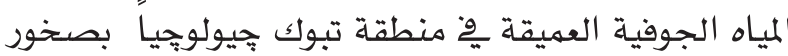
حقب الحياة القديمة، والمتمثلة يٌّ متكوني تبوك والسـاق. وبدراسـة جيولوجية منطقة الدراسة، يتضح أن المسامية و النفاذية Perosity الرملية ساعدت على تخزين المياه الجوفية بكميات كبيرة جداً، وهذا يجعل المياه سهلة التحرك خلاهل مساماتها، وينعكس على الإنتاج العالي من المياه الجوفية ( الصالح، $(199 \mathrm{~V}$

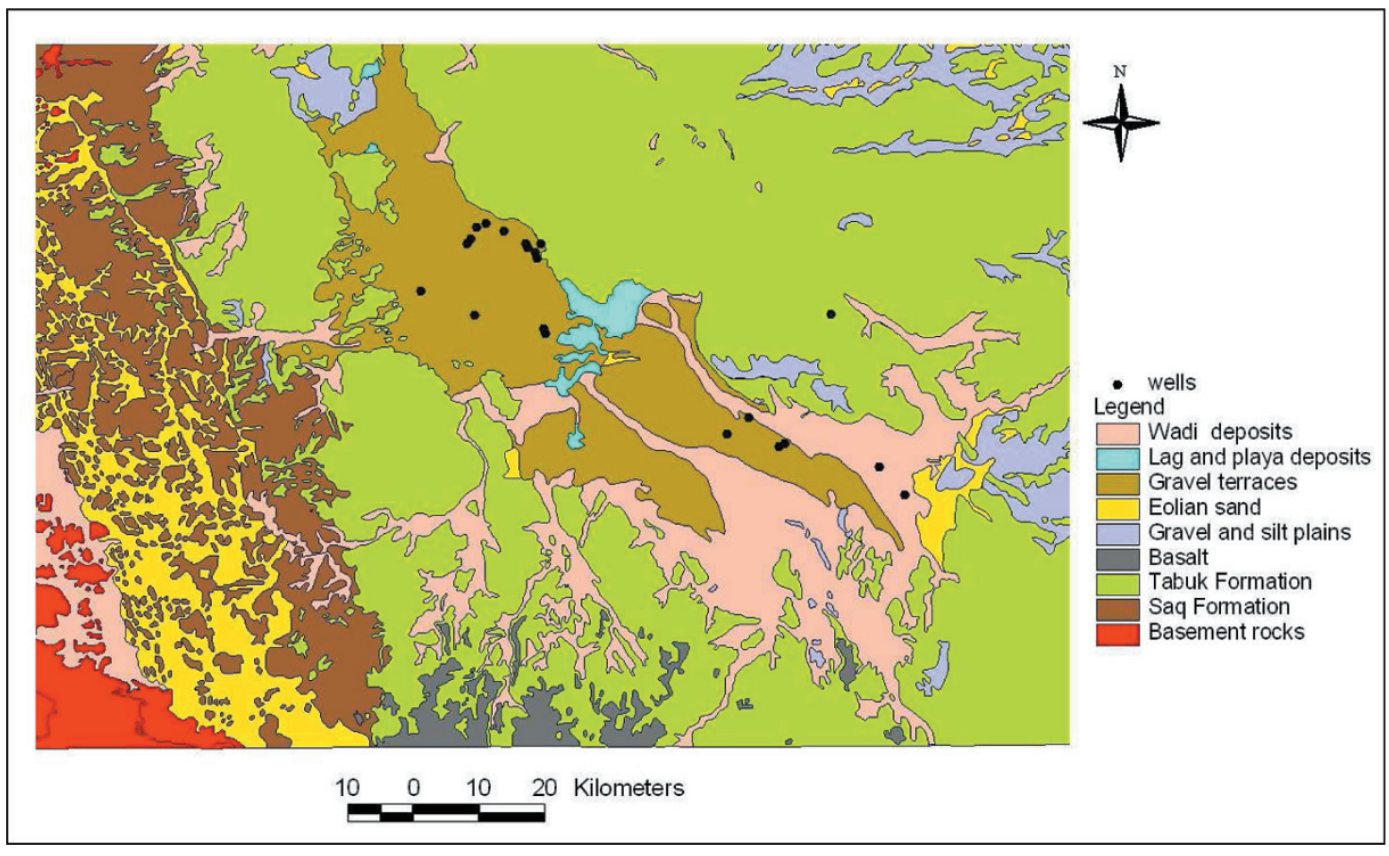

شكل (r) التكوينات الجيولوجية ومواقع آبار المياه الجوفية بهنطقة الدراسة

الدراسات السابقة:

تعد المياه الجوفية العميقة من الموارد المائية الرئيسة بو المملكة العربية السعودية، لذا فقد درست بتعمق من خلال العقود الحكومية التي أبرمت بين وزارة الزراعة والمياه آنذالك، وعدد من الشركات الأجنبية المتخصصة وِّ دراسة الموارد المائية وتقويهها. وقد ساهمت تلك الدراسات وِّ التعرف على كميات المياه المتوفرة بِّ التكوينات المائية

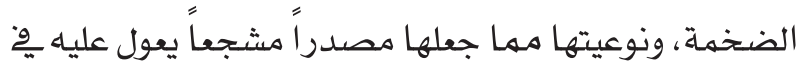
تتفيذ المشروعات الزراعية الكبيرة لتحقيق الأمن الغذائي
وبدراسة الخرائط الكنتورية لسطح المنطقة، يتبين أنها هضبة لا يزيد إرتقاعها عن • ㅅ متر عن مستوى سطح

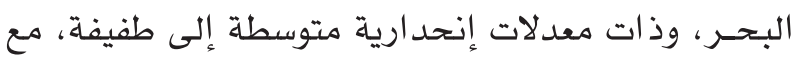
تميزها بمنظومة من أحواض التصريف الداخلية، بتأثير الجريان السطحي الموسيمي والمتعاقب. وتساهم تلك المنظومة على نقل المواد الرملية والطينية وترسيبها عند مصاب الأودية، وتمتد على مساحات شاسعة يِّ شمال وشرق تبوك. ومن أهم أحواض التصريف حوض وادي الأخضر، وحوض وله وادي أبو نشيفة، وحوض وادي ضهم الذي يستغل زراعياً بشكل كبير. 
لإختبار العلاقة بين TDS وباقي المركبات الكيمائية للمياه.

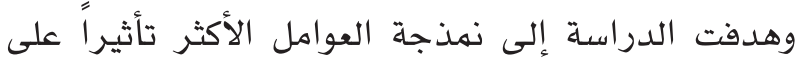

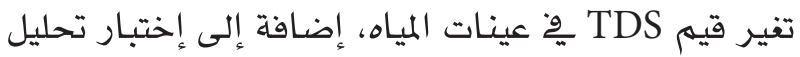

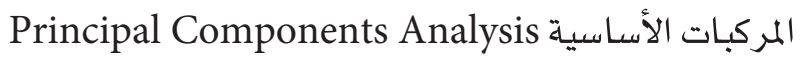

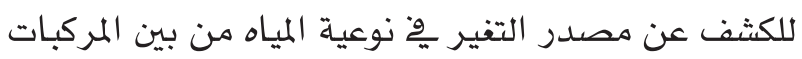
الكيمائية المكونة لها، وقد وقد خلصت الدراسة إلى توضيح

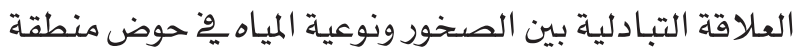

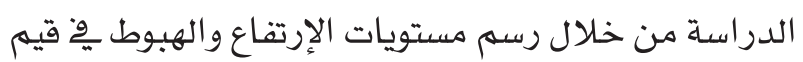
مجموع الأملاح الذائبة TDS لعينات الدراسة. وقد ناقشت بعض الدراسات الجفرافية طريقة إستخدام تقنية نظم المعلومات الجفرافية، كبرنامج 9.2 ARC GIS

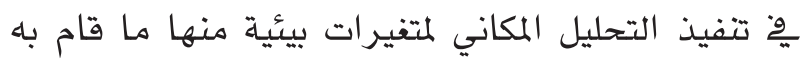

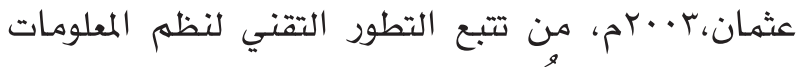

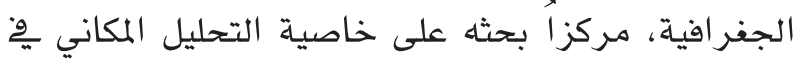
دعم القرار، مع التطبيق على بيئة المملكة العربية السعودية. كما قام عفت و حجازي (Effat and Hegazy، 2009) بتطبيق نظام معلومات جغراوٌْ متعددة الاشتراطات Multi-Criteria GIS المصرية وتقييهها بهدف تحديد المناطق المناسبة للزراعة. ويعد التعرف على نهط توزيع مواضع المياه الجوفية "

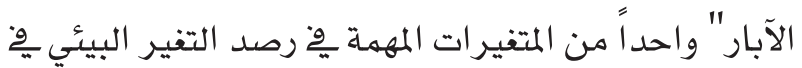
المناطق الجافة، التي تصبح دراستها على درجة عالية من التن

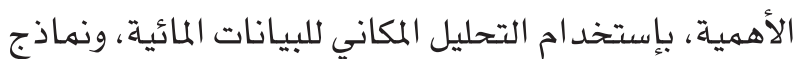
الإرتقاعات الرقمية Digital Elevation Models . وهو هذا الإطار، قام حماد (Hamad، 2009) بدراسة تحليلية،

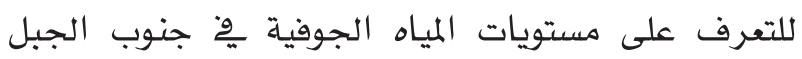

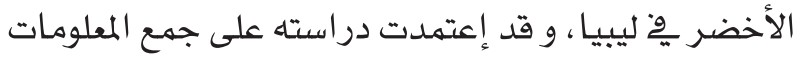

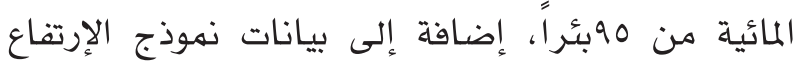

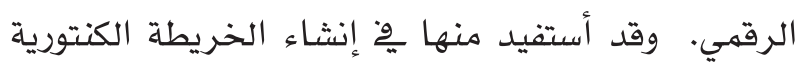
للمنطقة، وهي خريطة تظهر مستويات المياه الجوفية. كما

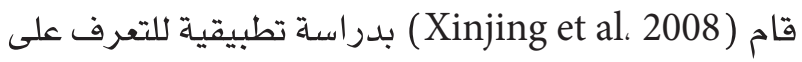
العلاقة بين التفير وِّمستويات المياه الجوفية، وإختلاف نوعية إستعهالات الأراضي وْ منطقة مختارة من جمهورية الصين، عن طريق منهج تكاملي إستخدم فيه الإستشعار

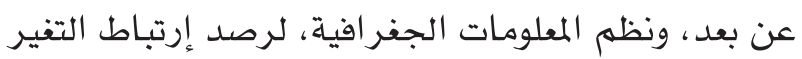
وِّ2 مستويات المياه بتغير إستعهالات الأراضي مكانياً وزمنياً.
وأنجزت العديد من الدراسات المتخصصة عن المياه الجوفية العميقة وغير العميقة بإستخدام الأساليب الإحصائية. ومنها ( Abdelmonem et al.، 1990 ) عن الصفات الكيميائية والتلوث البكتيري للمياه الجوفية

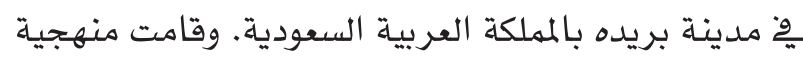

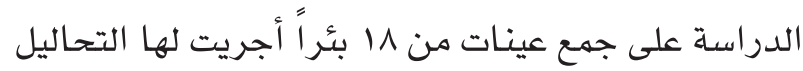

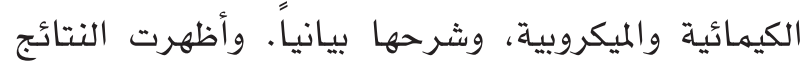

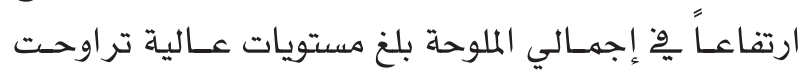

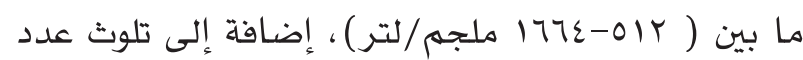

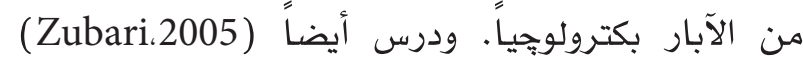

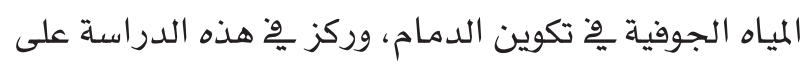

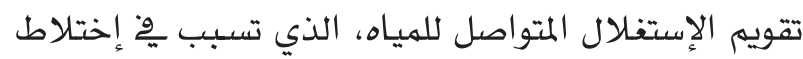

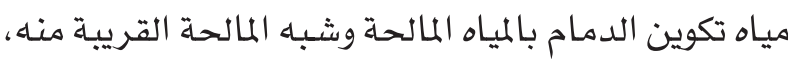

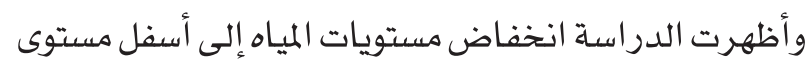

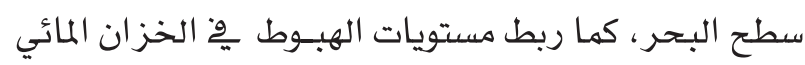

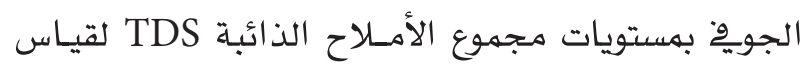

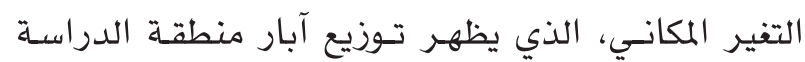
المرتبطة بقيم TDS، وكذلك تقييه التفير الزمني لقيهم

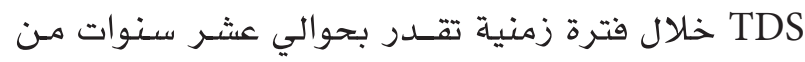

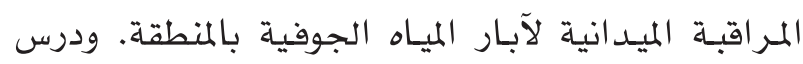
(Subyani and Bayumi، 2001)

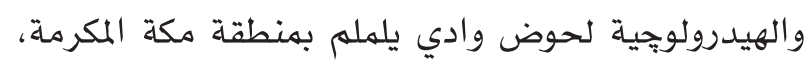

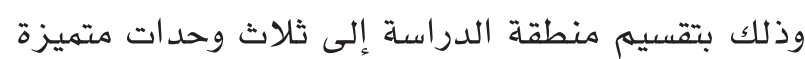

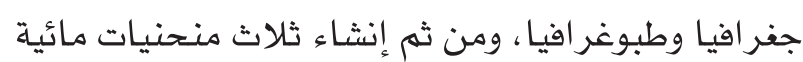

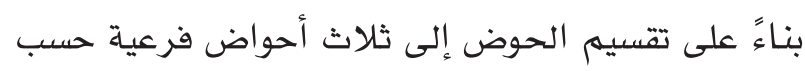

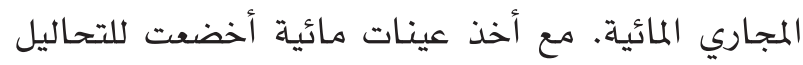
الكيميائية. وقَدر ( Bayumi، 2008) كميات مصادر المياه

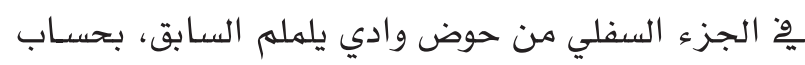

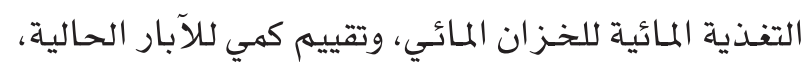

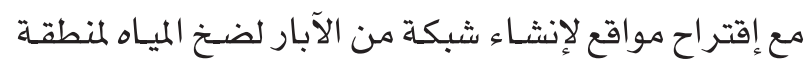

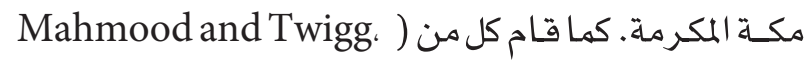

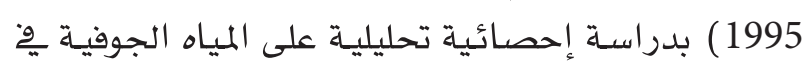

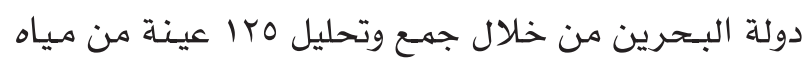

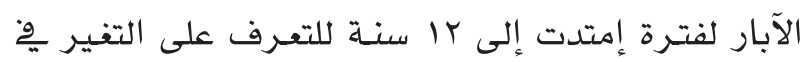

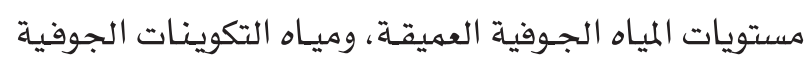
القريبـة من السطح. وقيَمَ ) Chenini and Khemiri، 2009) نوعية المياه الجوفية بإستخد ام معادلة خط الإنحدار 


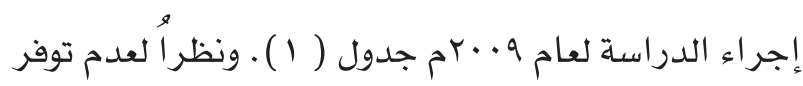
بيانات أبار المر اقبة من منطلق أن الشركات الزبات الزراعية العاملة

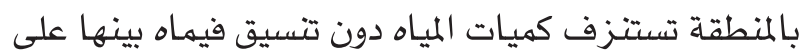
الرغم من وجود أدارة لمراقبة وتتمية قطاع المياه بهنطقة

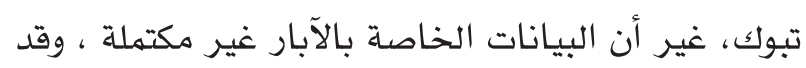

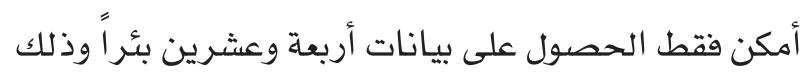

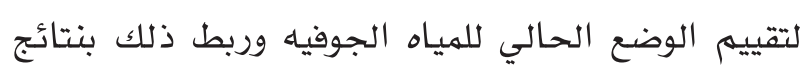

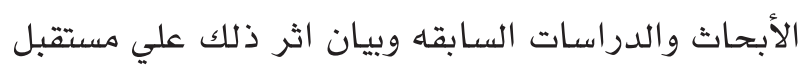
التنمية بالمنطقة.

\section{「- نموذج الإرتفاع الرقمي ومور الأقمار الإمطناعية:}

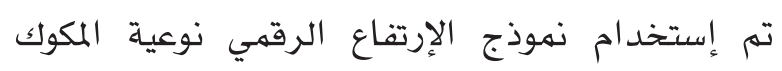

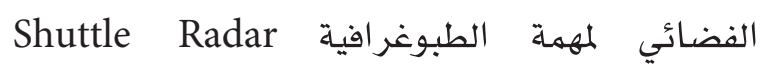
لتحديد وتمثيل نهط Topography Mission (SRTM) التصريف بطريقة أتوماتيكية بإستخدام الطرق التحليلية المرفقة ببرامج نظم المعلومات الجغرافية ARC-GIS

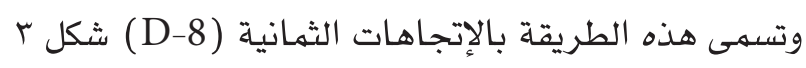
وشكل ع. وتعتمد هذه الطريقة على حساب النظام الشبكي

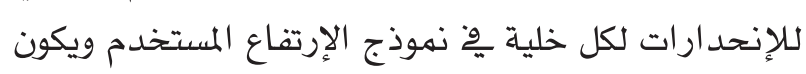
الإتجاه المحلي للإنحدار بإتجاه الخلية المحيطة الأقل قيمة لإنة

عِّ2 الإنحدار (El Bastawesy، et al.، 2009). ويته تحديد شبكة الإنحدار العام بطريقة الإشتقاق

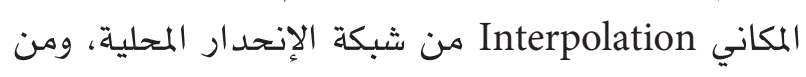
ثم يهكن تحديد قيم بدايات رتب أو أفرع الأودية الثانوية وِّ شبكة الإنحدار العام، إضافة إلى مضاهاة شبكة الأودية

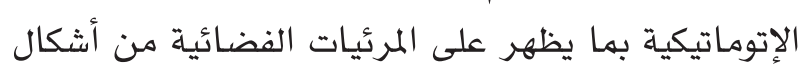

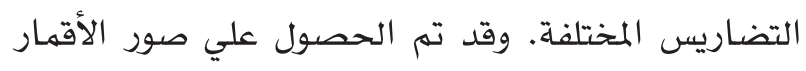

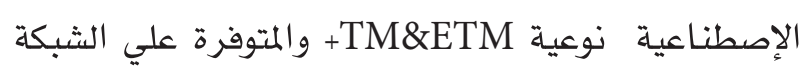
الخاصة بهيئة المساحة الجيولويحة الأمريكية لمنطقه

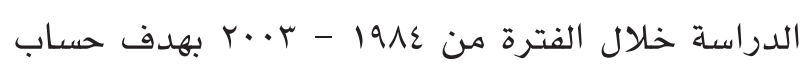

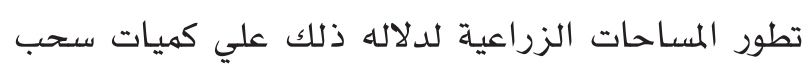

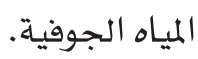

منهي الدراسة:

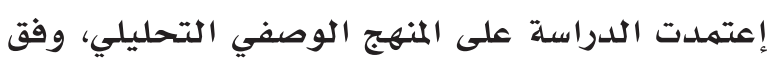

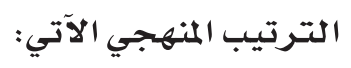

جمع المعلومات

\section{I- البيانات الهيدرولوجِية للمنطقة:}

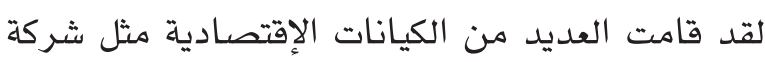

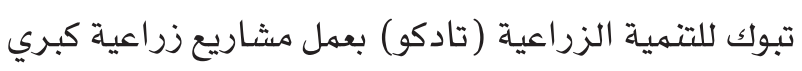

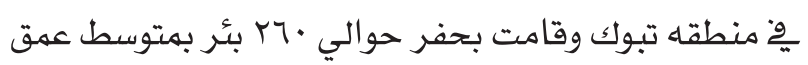

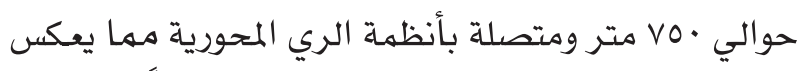
مقد ار سحب المياه الجوفية من المنطقة وخصوصاً من متكون الساق (Al-Ahmadi،2009). حيث يعتبر خزان السـاق

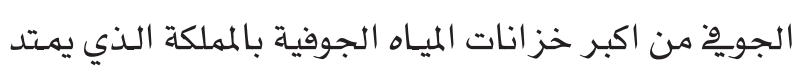

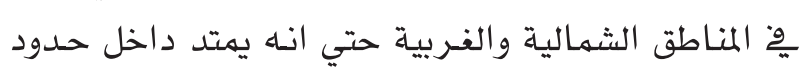

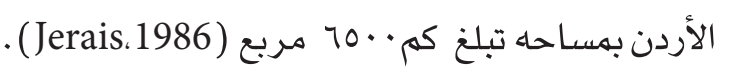

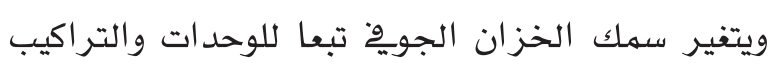

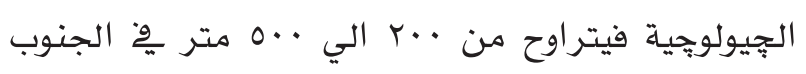

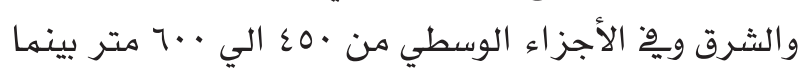

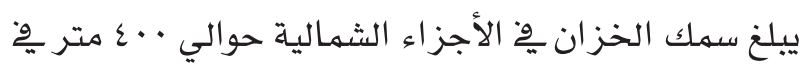

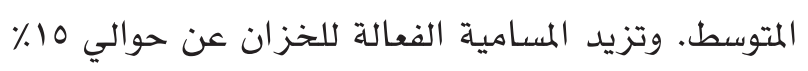

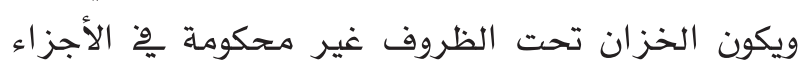
الجنوبية والفر بية حيث تنكثف صخور الحجر الرمان الرملي لمتكون

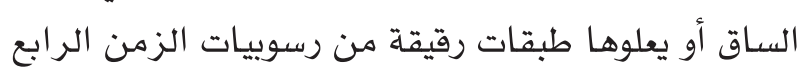

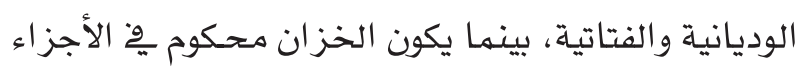

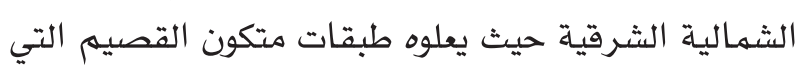
تتكون من تبادل طبقات الطفل والحجر الرملي الأردوفيشي.

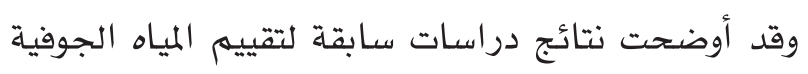

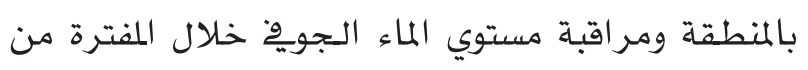

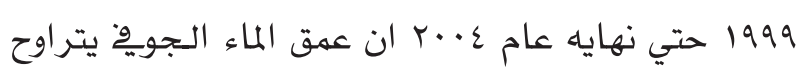

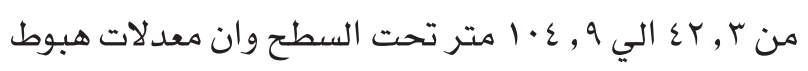

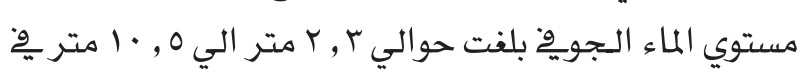
السنة (Al-Ahmadi،2009). ووِّْ هذا البحث تم تجميع بيانات لآبار المياه الجوفية

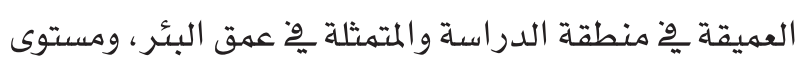

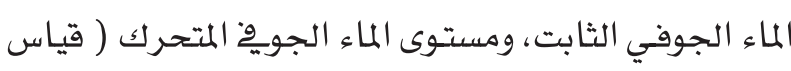

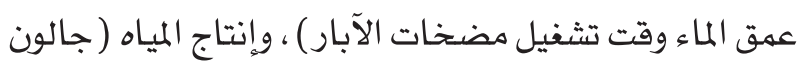

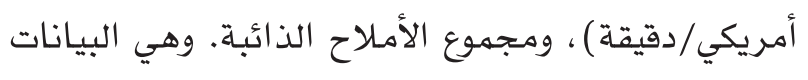

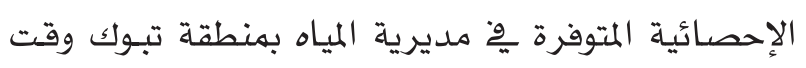




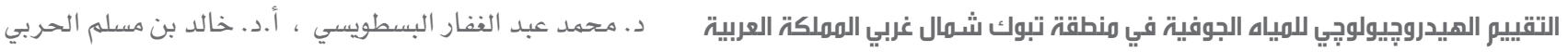

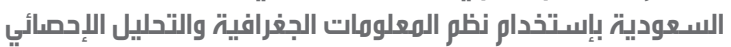

جدول ( 1 ) الخصائص الهيدرولوجية العامة لأبار المياه الجوفية بهنطقة تبوك

\begin{tabular}{|c|c|c|c|c|c|c|c|}
\hline ملجمهوع الأملاح & أنتاج المياه & و الفرق بين & الماء الجتوى & الماء الجويخ & البئر (متر) & رقم البئر & الجنغرافية \\
\hline$\varepsilon r r$ & $v \cdot \cdot$ & $r \cdot$ & 11. & 10 & $v \cdot \cdot$ & 1 & \multirow{16}{*}{ شمال آبار المنطقة } \\
\hline r. & $17 \ldots$ & $r \cdot$ & 11. & 17. & 9. & r & \\
\hline ¿ov & $1 \cdots$ & $r \cdot$ & iv. & 10 & $\wedge \cdot \cdot$ & r & \\
\hline raq & $1 \ldots$ & $r$. & iv. & $1 \varepsilon$. & $\wedge \cdot \cdot$ & $\varepsilon$ & \\
\hline $0 \cdots$ & 70. & $\varepsilon \cdot$ & $1 \wedge$. & $1 \varepsilon$. & $7 \cdot$. & 0 & \\
\hline so. & $\wedge \cdots$ & $\varepsilon$. & 11. & $1 \varepsilon$. & $7 \cdot$. & 7 & \\
\hline $7 .$. & Mr. & $r \cdot$ & 19. & 17. & $v \cdot \cdot$ & v & \\
\hline $7 \varepsilon$. & $\wedge \cdot \cdot$ & $r \cdot$ & 19. & 17. & $v \cdot \cdot$ & $\wedge$ & \\
\hline $7 .$. & $\wedge \cdots$ & $r$. & IV. & $1 \varepsilon$. & v. & 9 & \\
\hline $7 \cdot$. & $0 .$. & 0. & $r \cdot$. & 10 & $7 \cdot$. & 1. & \\
\hline $7 \ldots$ & $0 \ldots$ & 0. & $r \cdot$. & 10. & 70. & 11 & \\
\hline 70. & $0 \cdots$ & 0. & $r \cdot$. & 10. & 70. & Ir & \\
\hline $7 .$. & $0 \ldots$ & 0 . & $r \cdot$. & 10. & 70. & Ir & \\
\hline $7 .$. & $0 \cdots$ & 0. & $r \cdot$. & 10. & 70. & $1 \varepsilon$ & \\
\hline $7 .$. & $\wedge \cdots$ & $r \cdot$ & 11. & 10. & $7 \cdots$ & 10 & \\
\hline $7 .$. & $\varepsilon 0$. & $\varepsilon$. & $r \cdot$. & 17. & 70. & 17 & \\
\hline 00 & $\vee \cdot$ & $\varepsilon \cdot$ & iv. & $\mu$. & 0. & IV & \multirow{8}{*}{ شرقار آزراعية } \\
\hline 70. & $\wedge \cdots$ & $r \cdot$ & 17. & 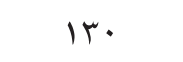 & 00. & 11 & \\
\hline $7 .$. & $r \cdot$. & $r \cdot$ & ir. & $1 \cdots$ & ¿o. & 19 & \\
\hline 70. & $r \cdot$. & $r \cdot$ & 10. & Ir. & $\varepsilon 0$. & $r \cdot$ & \\
\hline $7 .$. & $r \cdot$. & 10. & $r \cdot$. & 0. & r.. & rI & \\
\hline $7 .$. & $7 \ldots$ & $r \cdot$ & iv. & $1 \varepsilon$. & $\varepsilon 0$. & rr & \\
\hline $7 \cdots$ & $\varepsilon \cdots$ & $r \cdot$ & 17. & $1 \%$ & $0 \ldots$ & r & \\
\hline $7 .$. & $7 \ldots$ & $r$. & $1 \varepsilon$. & 1 & $0 .$. & $T \varepsilon$ & \\
\hline
\end{tabular}

المصدر: المديرية العامة للمياه بهنطقة تبوك (Y.9. ( ). 


\section{"-المراجعة الحقلية:}

تمت المراجعة الحقلية لكافة آبار المياه الجوفيــة بو

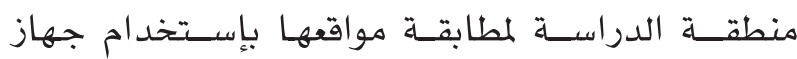
GPS - GARMIN 276C والموضحة على الشكل (r).

\section{ع- التحليل الإحمائي:}

تم إجراء التحليل الإحصائي على المصفوفة الإحصائية المؤلفة من الخصائص الهيدرولويجية العامة لآبار المياه

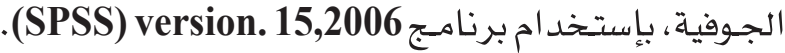

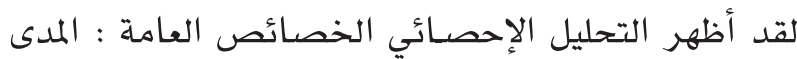

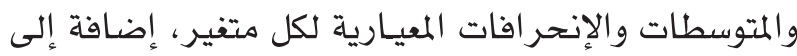
الكثف عن القيم الإرتباطية (معامل إرتباط بيرسون) Pearson correlation بين المتغير ات عند مستوى دلالـة

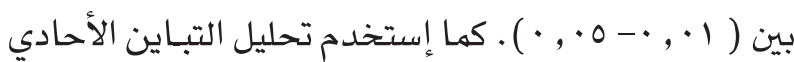
للتعرف على الفروقات الإحصائية بين (ANOVA) منطقتي شمال وشرق تبوك الزراعيتين للمتفيرات السابقة.

\section{النتائج والمناقشة:}

\section{تحليل الخريطة الحيولوجِية :}

تم ترقيم الخريطة الجيولوجية ا: ....0 التي تفطي منطقة الدراسة والمصححة جيومترياً مع نماذج الارتقاعات الرقمية والمرئيات الفضائية لمنطقة الدراسة. وبناءً على تلك الك الكاتهات الخطوة، تم تحديد ورسم العلاقة بين الطبقات المنكثفة لحوض التصريف والتتابع الجيولويجي والتركيبي للمنطقة. والمراجعة الآلية للخريطة الجيولوجية المصححة مع نماذج الإرتقاعات الرقمية والمرئيات الفضائية لمنطقة الدراسة تظهر حوض التصريف الداخلي المشتمل على عدد من الإنفاع

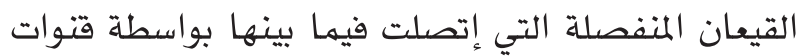
فيضية، وقد تأثرت رواسب الوديان بهجموعة الفوالق Faults ذات الإتجاه شمال غرب- جنوب شرق وهو الإتجاه السائد لمنطقة البحر الأحمر وبالتالي تكونت بعض الجالت القيعان والسبخات الجافة بداخل منطقة التصريف الداخلي نتيجة

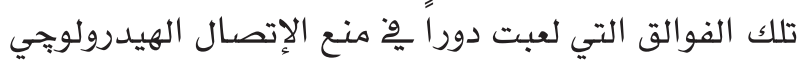

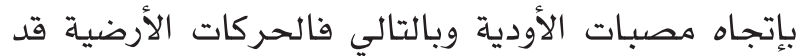

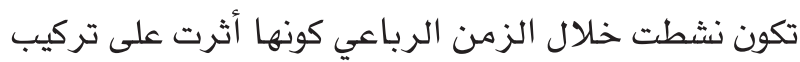
الرسوبيات وِّ المنطقة. وكثف تحليل الخريطة الجيولويجية

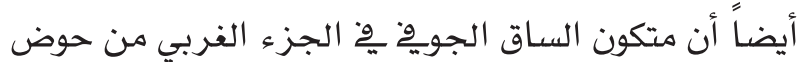

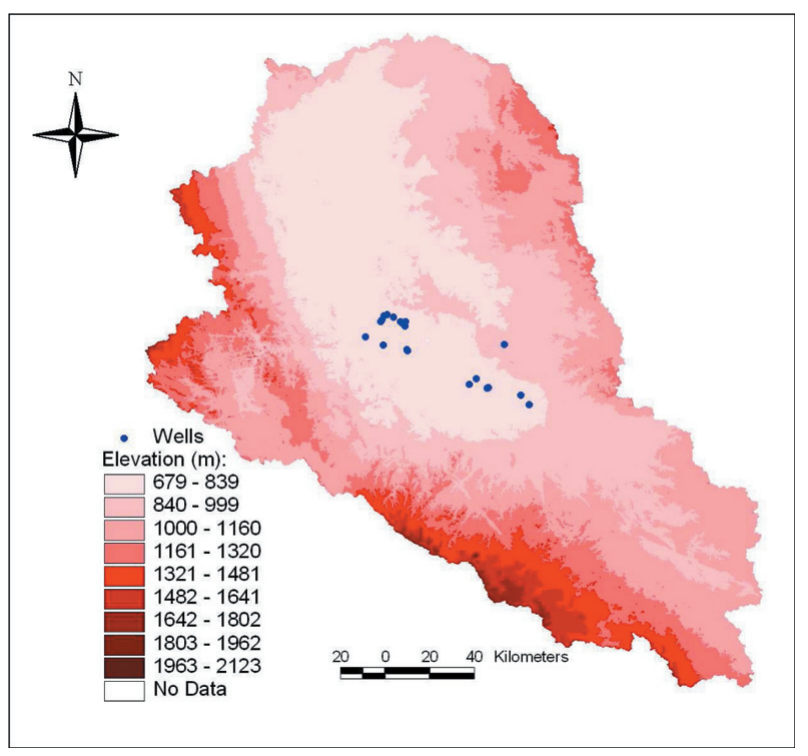

شكل (r) نموذج الإرتفاع الرقمي ومواقع الآبار

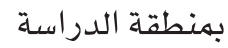

وقد ساعد نموذج الإرتقاع الرقمي لمنطقه الدراسة الموضح

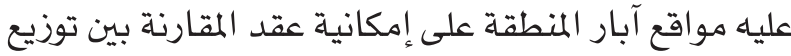
الإرتقاعات النسبية لحوض الصرف وتوزيع الوحدات الصخرية بالنظر إلى شكل Y حيث تنكثف صخور متكون

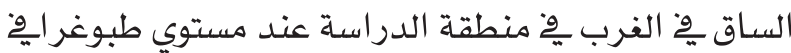
أعلي من متكون تبوك الأحدث جيولوجيا مها يدل علي تأثير الحركات الأرضية وِّ إعادة ترتيب وتوزيع مكاشف ومكامن الطبقات الحاملة للمياه الجوفية.

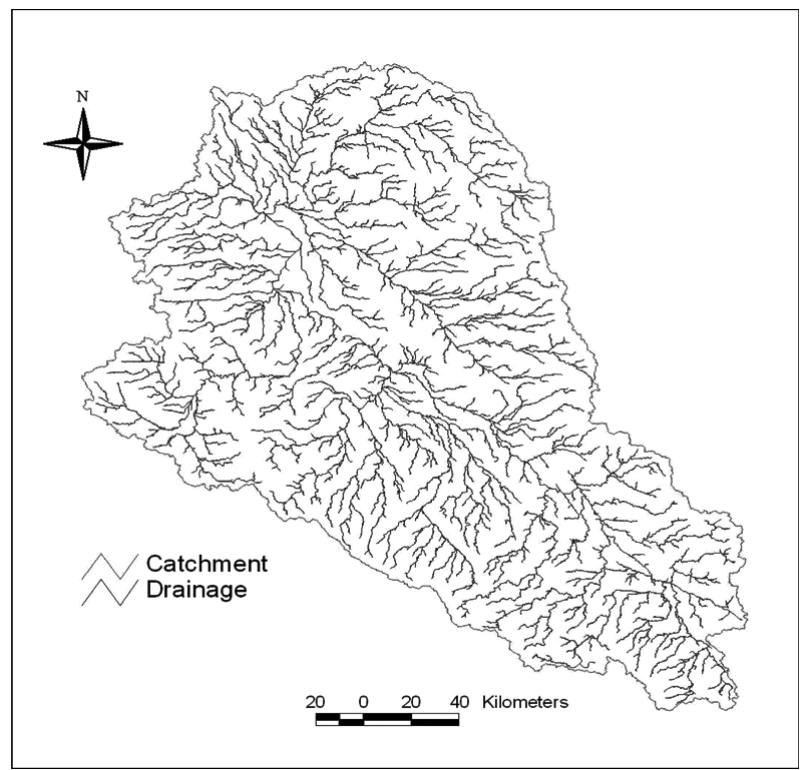

شكل (ع) شبكة التصريف السطحي بمنطقة الدراسة 


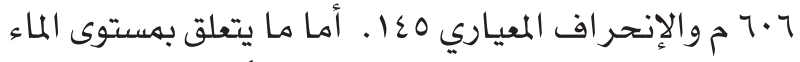

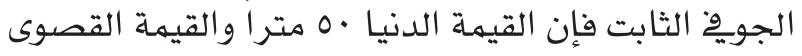

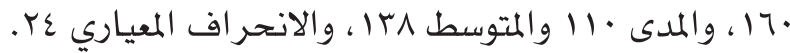
ويمثل مستوى الماء الجوبِّ المتحرك المتفير الذي يعكس مقدار تعمق المياه ِّ2 الطبقات الحاملة، حيث سجلت القيمة الدنيا

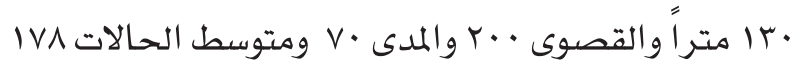

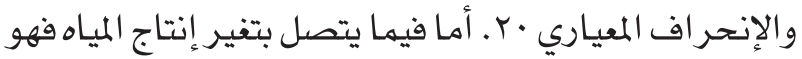
لا يختلف عن باقي المتغيرات السابقة، من حيث الإختلاف الكبير بين القيم الدنيا والقيم القصوى، حيث بلغت القيمة

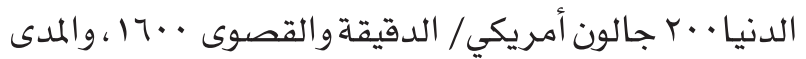

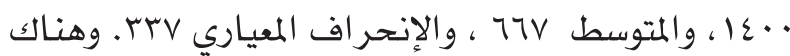

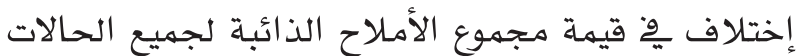

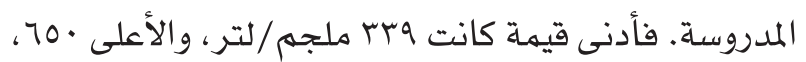

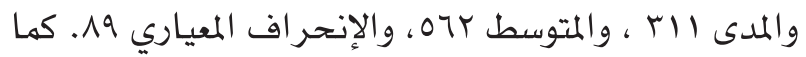

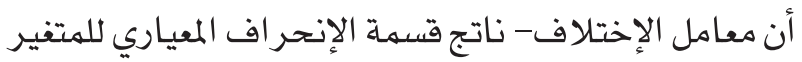

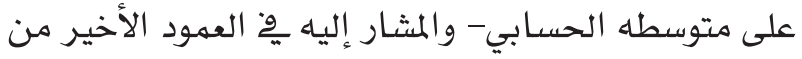

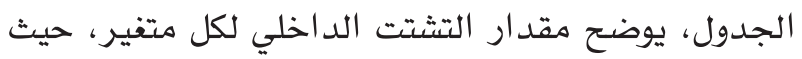
يلاحظ أن إنتاج المياه بين الآبار هو المتفير الأكبر تبايناً

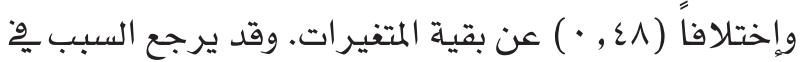

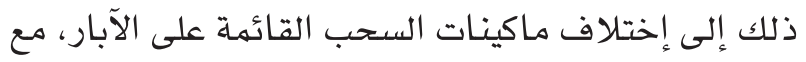

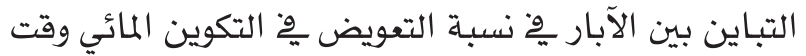

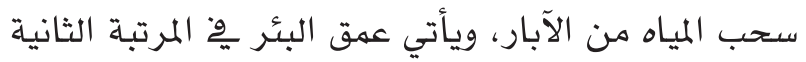

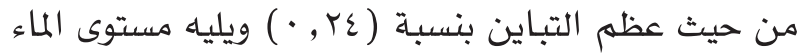

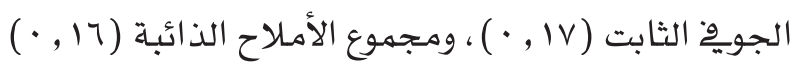

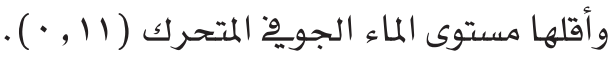

التصريف هو أعلي طبوغرافيا من متكون تبوك الأحدث جيولوجياً ويدل هذا الإختلاف على دور الحركات الأرضية

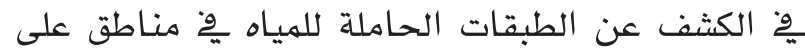

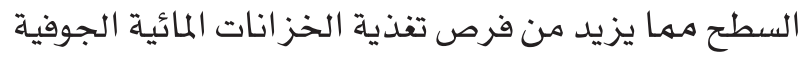
بمياه الإمطار.

\section{التحليل الجيمورفولوجيِ :}

يأخذ متكون الساق أشكال المصاطب الصخرية وكذلك الجزر المنعزلة المحاطة بكثبان وفرشات رملية تستطيل تلك الجزر بالإتجاه التركيبي السائد شمال غرب- جنوب شرق هما يدل على دور الحركات الأرضية پِّ تشكيل جيهورفولوجية تكوين الساق السطحي. وترتبط التمية الزراعية بأودية الأخضر وضمى وأبو نشيفة الكورية وكذلك بعدد من القيعان مها يؤثر على عملية تصريف المياه الزائدة عن الري حيث بد أت تظهر تجمعات للمياه السطحية

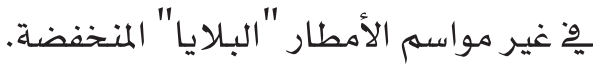

\section{التحليل الإحمائي :}

\section{I- الخمائم الميدرولوجية العامة لمتغيرات الدراست} يظهر الجدول( r) المؤشرات الإحصائية الأولية : القيم الدنيا والقيه القصوى والمدى والمتوسط والإنحر اف المعياري

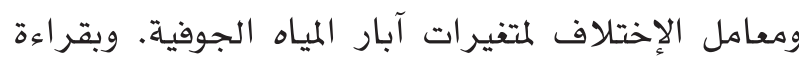

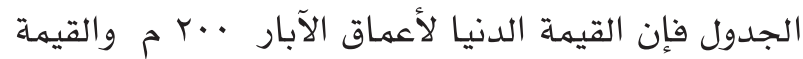

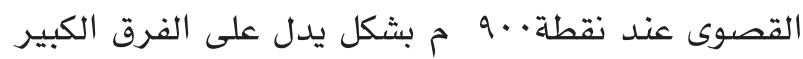

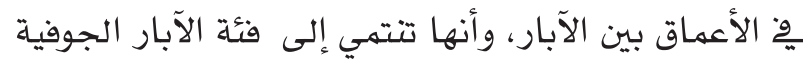

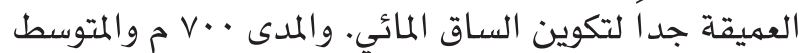

جدول (Y) الخصائص الإحصائية العامة لمتفيرات آبار المياه الجوفية بهنطقة الدراسة

\begin{tabular}{|c|c|c|c|c|c|c|}
\hline الإختاملافل معل & الإنحياري & المتوسط & المدى ال المى & القصوى القيمة & الديمـة الديا & المتغير \\
\hline$\cdot T \varepsilon$ & $1 \varepsilon 0$ & $7 \cdot 7$ & $\vee \cdot \cdot$ & $9 \cdot$ & $r \cdot$. & عمق البئر(م) \\
\hline $.1 \mathrm{~V}$ & $T \varepsilon$ & ire & 11. & 17. & 0. & مستوى الماء الجوٍِِ الثابت (م) \\
\hline .11 & r. & IVA & v. & $r \cdot$. & $1 r$. & مستوى الماء الجويِِ المتحرك(م) \\
\hline$\cdot \varepsilon \wedge$ & Mtr & $77 \mathrm{~V}$ & $1 \varepsilon \cdots$ & $17 \cdots$ & $r \cdot \cdot$ & إنتاج المياه جالون أمريكي /دقيقة \\
\hline .17 & 19 & $07 t$ & m1 & 70 . & rra & مجموع الأملاح الذائبة (ملجم/لتر) \\
\hline
\end{tabular}

المصدر: الباحثان بناء على جدول ( ) (1) 
لكلتا المنطقتين يعادل الضعف بوْ عملية السحب من الآبار، وبفارق يصل إلى ·.باجالون پِّ الدقيقة لصالح المنطقة

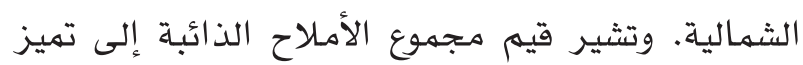
آبار المنطقة الشمالية بعذوبة أكثر للمياه مقارنة بشرقها.

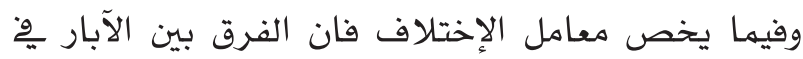

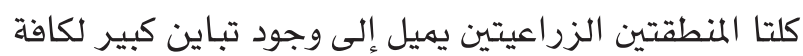

المتغير ات لصالح منطقة شرق تبوك مقارنة بشرقها.

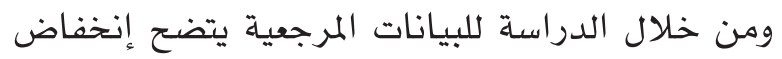

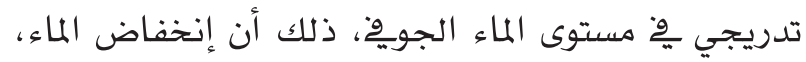

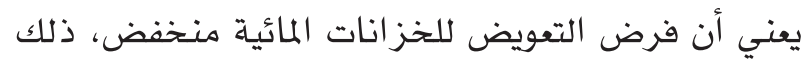

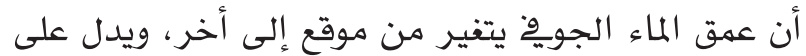

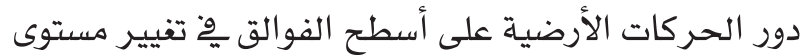

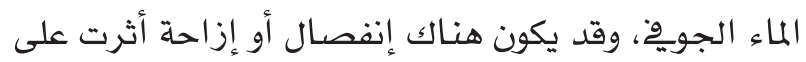

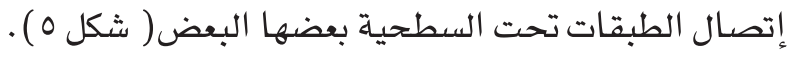

ولإظهار التفاوت بين المنطقتين الزراعيتين ِِّْمال وشرق تبوك، فان الخصائص الهيدرولوجية العامة لأبار المياه

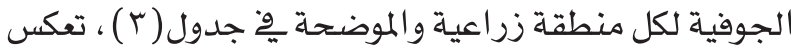
تبايناً احصائياً واضحاً عند المقارنة بين المنطقتينين لمتفير

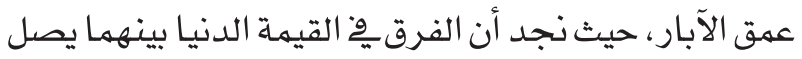

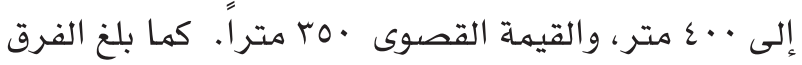

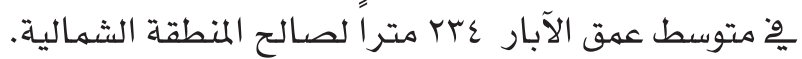

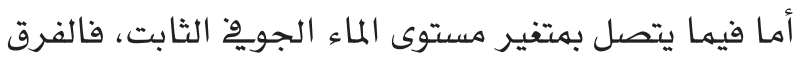

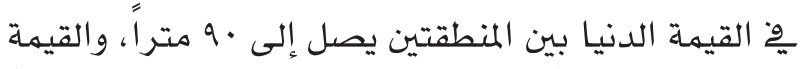

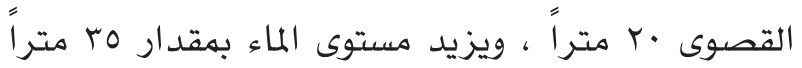

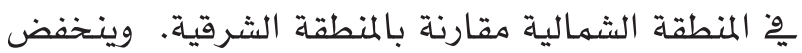
مستوى الماء الجوفو المتحرك ( وقت تشغيل مضخات المياه)

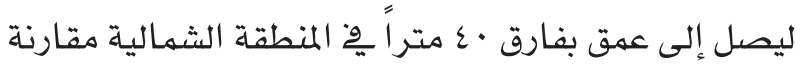

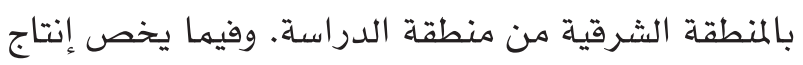

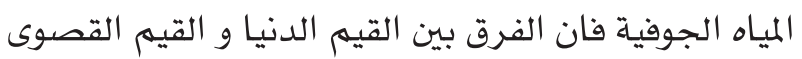

جدول (r) الخصائص الإحصائية العامة لمتغيرات آبار المياه الجوفية لمنطقتي شمال وشرق تبوك

\begin{tabular}{|c|c|c|c|c|c|c|c|}
\hline الإختالاف & الإنحراف & المتوسط & المدلى & القصوى القيمة & الديمـة الدنيا & ا المتغير & الجنطقرافية \\
\hline$\cdot$, IT & 10 & \urcorner$\wedge \varepsilon, r$ & $r \cdot$. & $9 \cdots$ & $7 \cdots$ & عمق البئر (م) & \multirow{5}{*}{ منطال تبوك } \\
\hline$\cdot, \cdot 0$ & $v, r$ & 10 & $r \cdot$ & 17. & $1 \varepsilon$. & مستوى الماء الجويٌِ الثابت (م) & \\
\hline$\cdot, \cdot 7$ & 11,9 & 117,1 & $r \cdot$ & $r \cdot \cdot$ & ive & مستوى الماء الجويِ المتحرك(م) & \\
\hline$\cdot, \varepsilon 1$ & rIr, & $\vee\urcorner \wedge, \vee$ & 110 & 00 & ¿o. & إنتاج المياه جالون /دقيقة & \\
\hline$\cdot, 19$ & $1 \cdots, 0$ & orq, r & m1 & $1 \varepsilon$ & rrq & مجموع الأملاح الذائبة (ملجم/لتر) & \\
\hline$\cdot, Y \varepsilon$ & $1 \cdot 7,9$ & $\varepsilon 0$. & ro. & 00 & $r \cdot$. & عمق البئر (م) & \multirow{5}{*}{ شرق تبوقة } \\
\hline$\cdot$, ro & rq, r & 110 & 9 . & $1 \varepsilon$. & 0. & مستوى الماء الجويٍِ الثابت (م) & \\
\hline$\cdot, 14$ & $r, r$ & 17. & v. & $r \cdot \cdot$ & ir. & مستوى الماء الجويِ المتحرك(م) & \\
\hline$\cdot$, or & $r \varepsilon \varepsilon, 0$ & $\sum \tau Y, 0$ & $7 \cdot$. & $\wedge \cdots$ & $r \cdot \cdot$ & إنتاج المياه جالون /دقيقة & \\
\hline$\cdot, \cdot 0$ & rt & $7 \cdot 7$ & $1 \cdots$ & 70 . & 00 . & مجموع الأملاح الذائبة (ملجم/لتر) & \\
\hline
\end{tabular}

المصدر: المديرية العامة للمياه بهنطقة تبوك (9 +rم) 


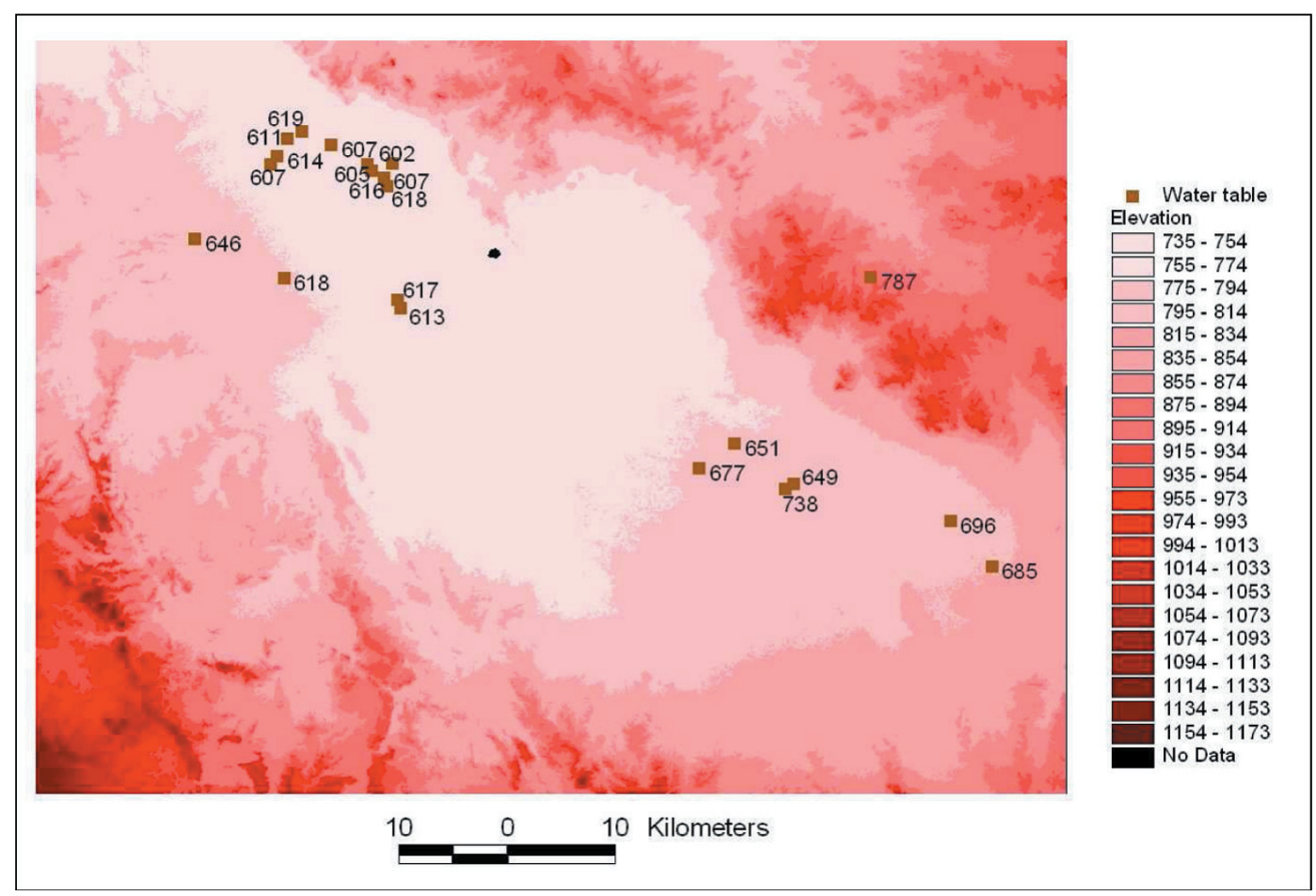

شكل (0) مستويات المياه بِّ الآبار وارتقاعاتها بمنطقة الدراسة

الوفرة المائية الكبيرة. وتبينً من التحليل الإحصائي عدم

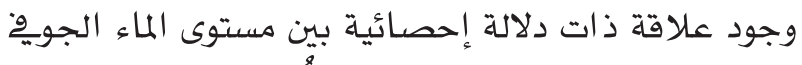

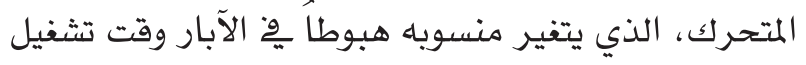
مضخات سحب المياه وباقي المتغير ات الأخرى. وتفسير ذلك الك الكار وقت تشفيل

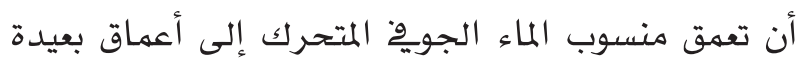

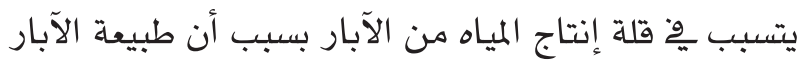

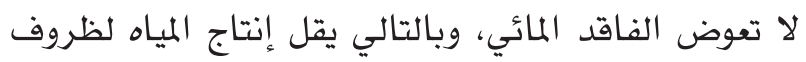

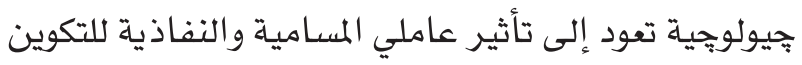
المائي.

\section{「- العلاقات الإرتباطية بين متغيرات آبار المياه}

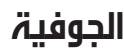

ساعد التحليل الإحصائي وْ الكثف عن علاقات إرتباطية

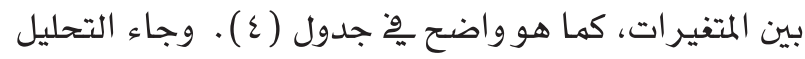
بعلاقة طردية بين عمـق آبار الميـاه الجوفيـة وإنتاجيتها

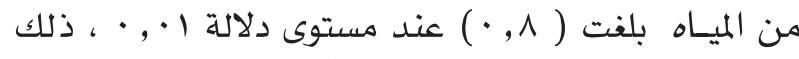

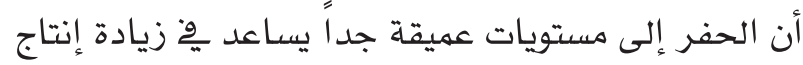
المياه بمعدلات عالية، وبخاصة ِِّ مناطق التكوينات المائية الوافرة. وعلاقة طردية بين عمق الآبار ومستوى الماء الجويوّاه

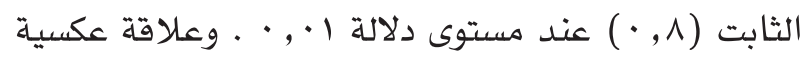

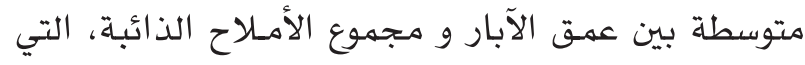

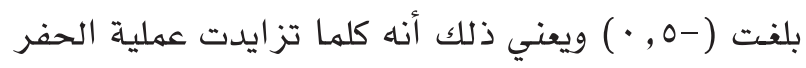
وسحب المياه من أعماق كبيرة، يؤدي إلى تحسن نوعية المياه

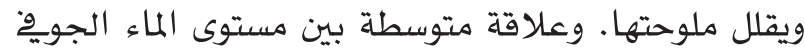

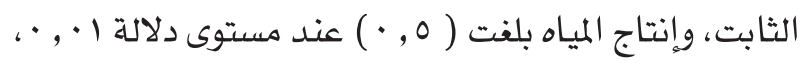
و ترتبط هذه العلاقة بهستوى العلاقة الطردية بين عمق العقاه

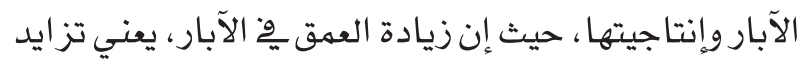

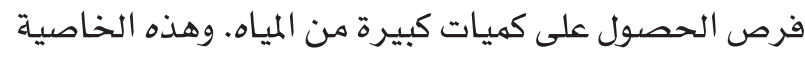

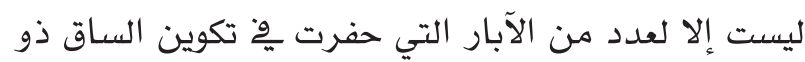




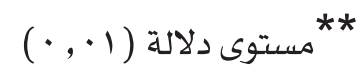

\begin{tabular}{|c|c|c|c|c|c|}
\hline ملأجم/الذائلة & جالون أمـريكي إنتاه & المتاء الجويفو & 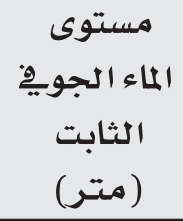 & 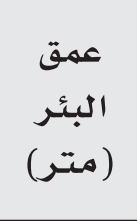 & العلاقة الإرتباطية بين المتغيرات \\
\hline$\cdot, 0{ }^{* *}$ & $\cdot, \wedge^{* *}$ & $\cdot, r$ & $\cdot, \wedge * *$ & 1 & عمق البئر \\
\hline$\cdot, \cdot$ & $\cdot, 0^{* *}$ & $\cdot, r$ & 1 & $\cdot, \Lambda^{* *}$ & مستوى الماء الجوبِِ الثابت \\
\hline$\cdot, \cdot$ & $\cdot, \cdot$ & 1 & $\cdot, r$ & $\cdot, r$ & مستوى الماء الجويِ المتحرك \\
\hline$\cdot, \cdot$ & 1 & $\cdot, \cdot$ & $\cdot, 0^{* *}$ & $\cdot, \wedge * *$ & إنتاج المياه جالون /دقيقة \\
\hline 1 & $\cdot, 7_{-}^{* *}$ & $\cdot, \cdot$ & $\cdot, \cdot$ & $\cdot, 0_{-}^{* *}$ & مجموع الأملاح الذائبة \\
\hline
\end{tabular}

المصدر: الباحثان بناءً على تحليل جدول ( )

\section{ب- تحليل التباين الأحادي ANOVA}

جدول (0) تحليل التباين الأحادي ANOVA

\begin{tabular}{|c|c|c|}
\hline الدلالةى & قيمة ( ف ) & المتغير \\
\hline$\cdot, \cdots$ & $r \varepsilon, I V 7$ & عمق البئر (م) \\
\hline$\cdot, \cdots$ & $r 1,1 r v$ & مستوى الماء الجوبِ \\
\hline$\cdot, \cdot 1$ & 10,109 & مستوى الماء الجوبِ \\
\hline r, ro & $0, \wedge Y \wedge$ & جالون/دقاج المياهة \\
\hline$\cdot, \wedge r$ & $r, r \cdot \Lambda$ & الذائبة ملجمع/الأملاح لتر \\
\hline
\end{tabular}

المصدر: الباحثان بناءً على جدول (1)
بإستخدام تحليل التباين الأحادي للكثف عن التباين بين

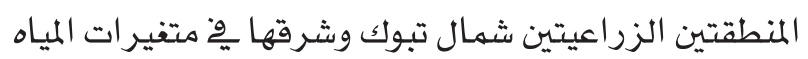

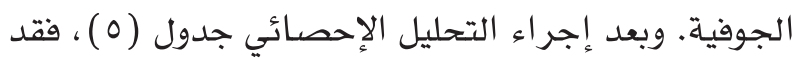

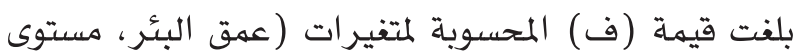

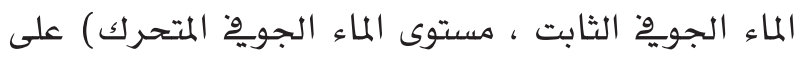

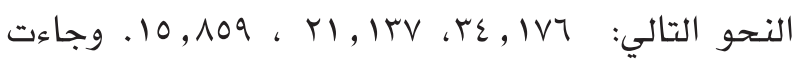
جميع القيه السابقة عند مستوى دلالة إحصائية ( ·, · · )

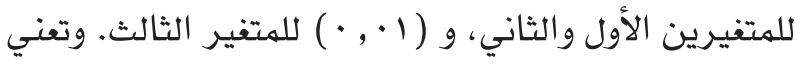

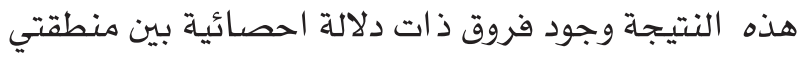

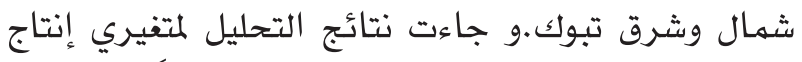

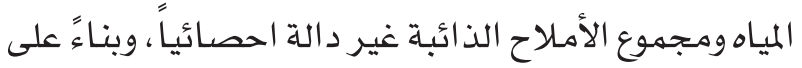
نتيجة التحليل، فانه لا يوجد فروقات ذات دلالة إحصائية

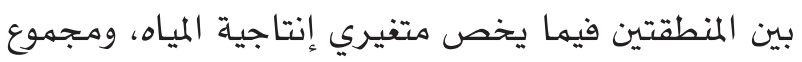

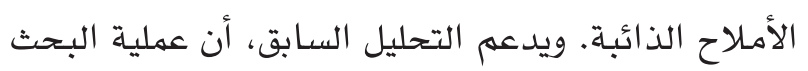

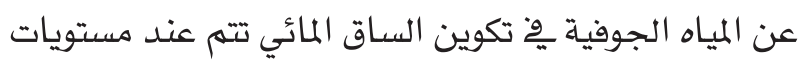

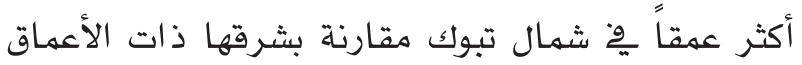

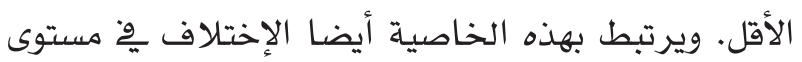

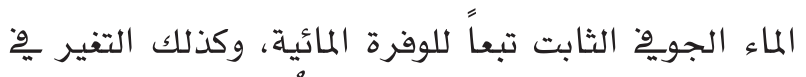

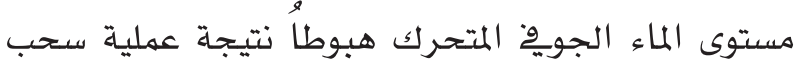
المياه الجوفية لري المحاصيل الزراعية. 
تحليل التباين الأحادي ANOVA الإختلاف بين المنطقتين

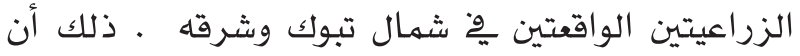

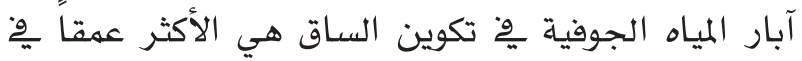

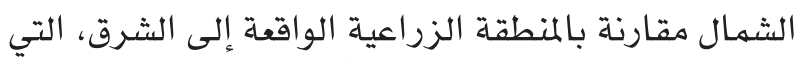

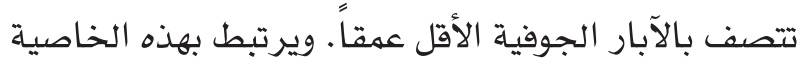
الإختلاف بوْ مستوى الماء الجوبِّ الثابت تبعاً لوفرة المياه ״وِ الخزانات المائية، وللتغير الذي يحصل على مستوى الماء الماء

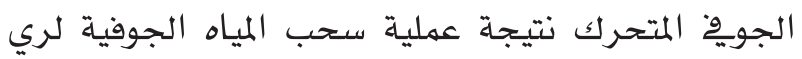

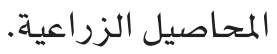

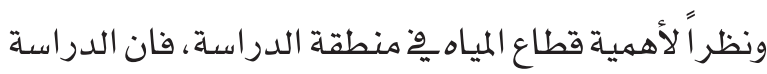
الحالية توصي بضرورة إجراء الدراسات الجفرافية المتخصصة لدراسة واقع ومستقبل المياه الجوفية وِ المنطقة

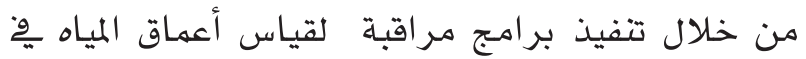

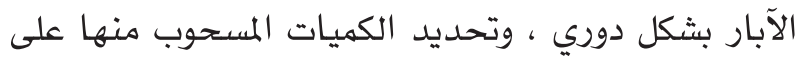

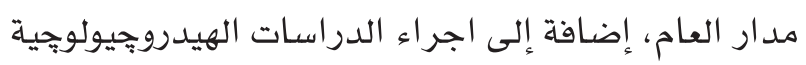

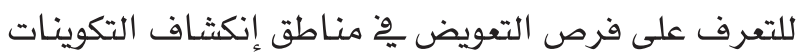
الحاملة للمياه الجوفية العميقة و غير العميقة ، مع العناية

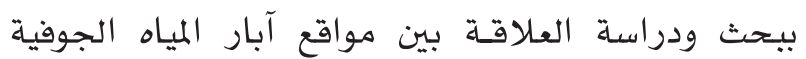
ومتغير الخطيات البنـائية لLineaments، و و تقويم أثر الثراه

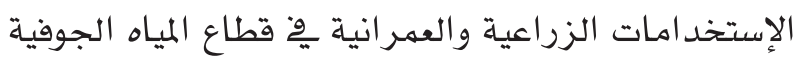
بهنطة الدراسة.

\section{الخاتمة والإلستنتاجات:}

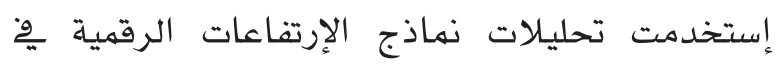

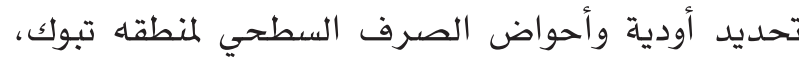

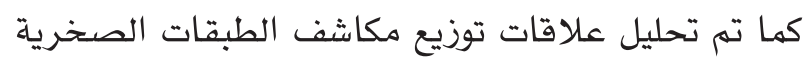

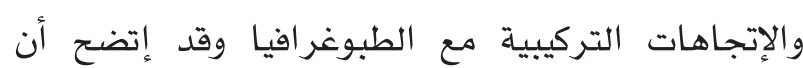

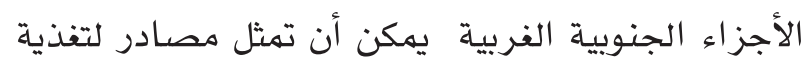

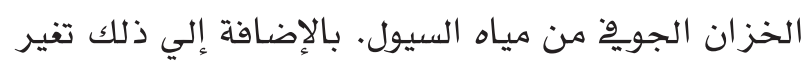

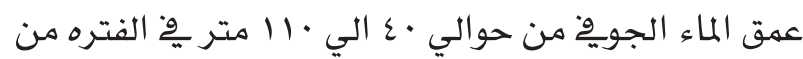

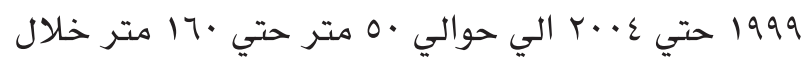

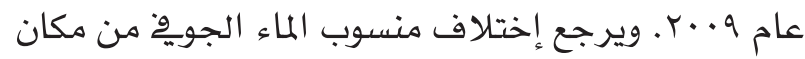

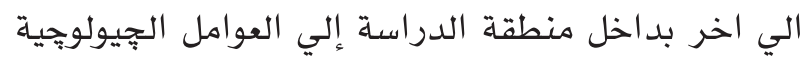

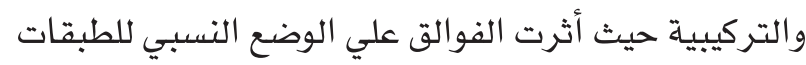

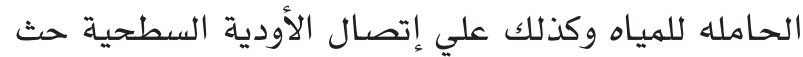
تكونت بعض البلايات بداخل قطاعات الأوديه الطوليه التي

انخفضت عما حولها بفعل الحركات الأرضية الحديثة.

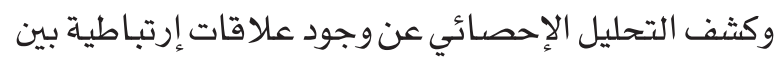

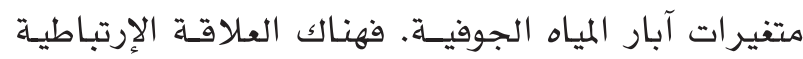

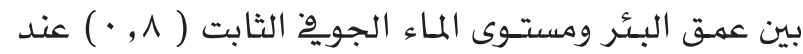

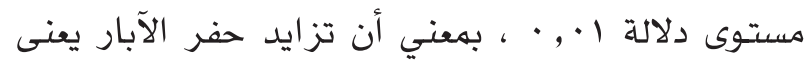

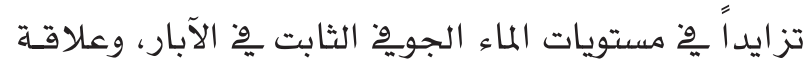

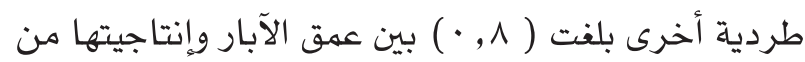

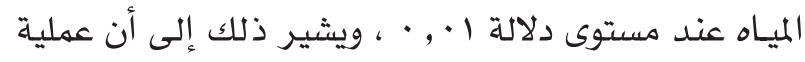
الحفر إلى مستويات عميقة جداً يساعد على زيادة إنتاج المياه بهعدلات عالية خاصة وِّ مناطق الوفرة المائية، وعلاقة

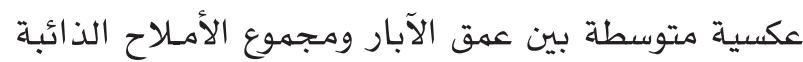

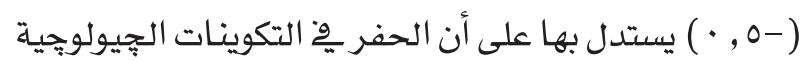

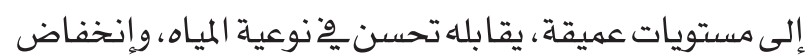
محتواها من مجموع الأملاح الذائبة لتجنب الترسبات

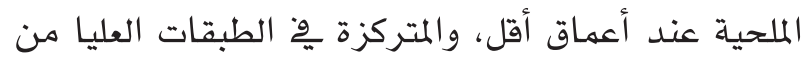
التكوينات المائية الجوفية، وعلاقة متوسطة بين مستوى الماقي المتركية

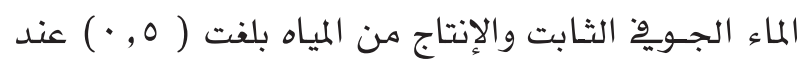
مستوى دلالة ا ., •. ولا توجد علاقة ذات دلالة إحصائية

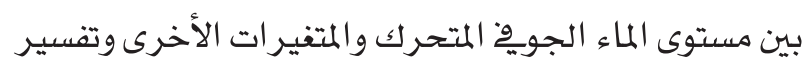

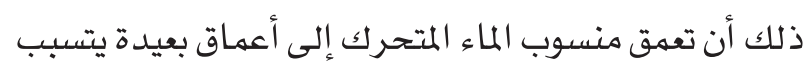

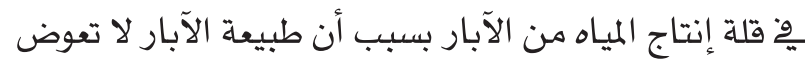

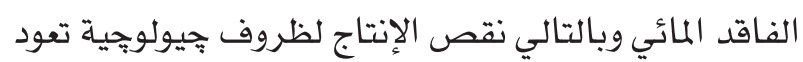

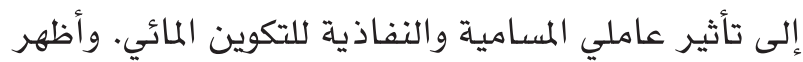


- Abdelmonem, A., El-Meleigi, M., Al-Rokaibah,

A. ( 1990). Chemical characteristics and bacterial contamination of groundwater in Buradah, Saudi Arabia. Journal of King Saud University, Agricultural Sciences. 2:279 - 290.

-Al Ahmadi, M.E., 2009. Hydrogeology of the Saq aquifer, northwest of Tabuk, northern Saudi Arabia, Journal of King AbdulAziz University: Earth Sciences, 20:51 - 66.

- Bayumi, T, H,(2008). Quantitative groundwater resources evaluation in the lower part of Yalamlam basin, Makkah Al Mukarramah, Western Saudi Arabia. Journal of King Abdullaziz University Earth Sciences. 19: 35 - 56.

- Chenini, I., and Khemiri, S. ( 2009). Evaluation of ground water using multiple linear regression and structural equation modeling, International Journal of Environmental Science Technology, 6: 509 - 519.

-El Bastawesy, M., White, K., and Nasr, A., 2009. Integration of remote sensing and GIS for modeling flash floods in Wadi Hudain catchment,

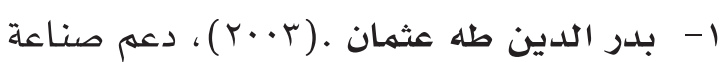

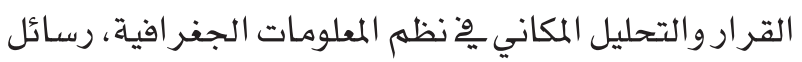
الجمعية الجفر افية الكويتية، العدد rVV، الكويت.

Y- الرئاسة العامة لكلأرصاد وحماية البيئة.

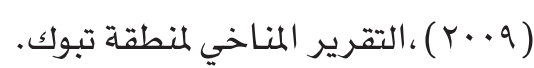

r- عبد الرحمن صادق الشريف. (r.r.r) ، جغر افية

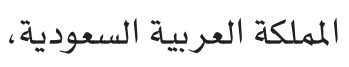
دار المريخ للنشر، الرياض.

ع- محمد عبد الله الصالح .(199V) ، دور الإستشعار عن بعد بِّ تنمية المياه

الجوفية، رسائل الجمعية الجفرافية الكويتية، العدد

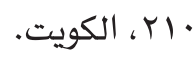

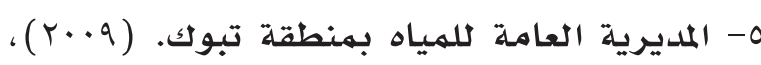
البيانات المائية لمنطقة تبوك. المامة لمكياه

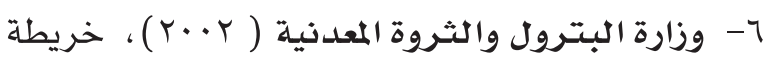

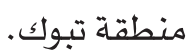

V- وزارة البترول والثروة المعدنية .( ( 1977 )، الخريطة

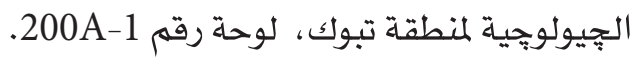
Egypt. Hydrological Processes, 23: 1359 - 1368.

- Effat, H., and Hegazy, M., 2009, Application of spatial multi criteria evaluation for an agricultural development scenario in the Egyptian deserts, Proceedings of the 16th International Symposium GIS, January 25 - 28, Ostrava, Czech Republic.

- Ghulam,A., Qin, Q., and Zhu,L, (2004). Satellite remote sensing of groundwater: quantitative modelling and uncertainty reduction using $6 \mathrm{~S}$ Atmospheric Simulations. International Journal of Remote Sensing, 25: 5509 - 5524.

- Hamad, S,(2009). Geostatistical analysis of groundwater level in the south Jabal AL Akhder 
using GIS. 16 ${ }^{\text {th }}$ International Symposium GIS's Ostrava, 2009, Czech Republic.

-Kayane,I. ， (1997). Global warming and groundwater resources in arid lands. In freshwater resources in arid lands. Ed Uitto,J., and Schneider., J.

- Mahmood, H and Twigg, D. (1995). Statistical analysis of water table variations in Bahrain. Quarterly Journal of Engineering Geology\& Hydrology. 28: 63 -74.

- Sakthivel, R., Manivel, M., and Alagappa, M. (2003) "Application of remote sensing data for delineation of ground water potential zones in the Kalrayan Hills, Tamil Nadu. Map Indian Conference. www.GIS development.com.

- Statistical Package for Social Sciences Incorporation (SPSS) version 15,(2006).

- Subyani, A, M and Bayumi, T, H( 2001). Physiographical and hydrological analysis of Yalamlam basin, Makkah Al-Mukarramah area. Journal of King Abdullaziz University Earth Sciences. 13: 151 - 177.

- Xinjing,X., Yan,J., Chen,Z Luo, G and Xu,W, (2008). A Geospatial analysis approach for assessing the impact of land use on groundwater resources in the SanGong Oasis Region. Journal of Agricultural Food, and Environmental Sciences. 2:1- 10 .

- Zubari, W.( 2005). Spatial and temporal trends in groundwater resources in Bahrain, 1992 -2002. Emirates Journal for Engineering Research. 10: 57 - 67. 